\title{
Functional Characterization of a Novel Truncating Mutation in Lamin A/C Gene in a Family with a Severe Cardiomyopathy with Conduction Defects
}

\author{
Andrea Gerbino ${ }^{a}$ Irene Bottillo ${ }^{b}$ Serena Milano ${ }^{a}$ Martina Liparib \\ Roberta De Zio ${ }^{a}$ Silvia Morlino ${ }^{b} \quad$ Maria Grazia Mola ${ }^{a}$ Giuseppe Procino ${ }^{a}$ \\ Federica $\operatorname{Re}^{c}$ Elisabetta Zacharac Paola Grammatico ${ }^{b}$ Maria Svelto ${ }^{a}$
}

Monica Carmosino ${ }^{d}$

aDepartment of Biosciences, Biotechnologies and Biopharmaceutics, University of Bari, Bari; ${ }^{b}$ Medical Genetics, Department of Molecular Medicine, Sapienza University, San Camillo-Forlanini Hospital; 'Cardiology Division, Cardiac Arrhythmia Center and Cardiomyopathies Unit, San Camillo-Forlanini Hospital, Rome; dDepartment of Sciences, University of Basilicata, Via dell'Ateneo Lucano, Potenza, Italy

\section{Key Words}

Laminopathies $•$ Nucleus $•$ Endoplasmic reticulum $•$ Connexin $\bullet \mathrm{Ca}^{2+}$ signaling $\bullet$ Cardiomyocytes - Lamin A/C gene

\begin{abstract}
Background/Aims: Truncating LMNA gene mutations occur in many inherited cardiomyopathy cases, but the molecular mechanisms involved in the disease they cause have not yet been systematically investigated. Here, we studied a novel frameshift LMNA variant (p.D243Gfs*4) identified in three members of an Italian family co-segregating with a severe form of cardiomyopathy with conduction defects. Methods: HEK293 cells and HL-1 cardiomyocytes were transiently transfected with either Lamin A or D243Gfs*4 tagged with GFP (or mCherry). D243Gfs*4 expression, cellular localization and its effects on diverse cellular mechanisms were evaluated with western blotting, laser-scanning confocal microscopy and video-imaging analysis in single cells. Results: When expressed in HEK293 cells, GFP- (or mCherry)-tagged LMNA D243Gfs*4 colocalized with calnexin within the ER. ER mislocalization of LMNA D243Gfs*4 did not significantly induce ER stress response, abnormal $\mathrm{Ca}^{2+}$ handling and apoptosis when compared with HEK293 cells expressing another truncated mutant of LMNA (R321X) which similarly accumulates within the ER. Of note, HEK293-LMNA D243Gfs*4 cells showed a significant reduction of connexin 43 (CX43) expression level, which was completely rescued by activation of the WNT/ $\beta$-catenin signaling pathway. When expressed in HL-1 cardiomyocytes, D243Gfs*4 significantly impaired the spontaneous $\mathrm{Ca}^{2+}$ oscillations recorded in these cells as result of propagation of the depolarizing waves through the gap junctions between non-
\end{abstract}

A. Gerbino and I. Bottillo contributed equally to this work.

Dr. Monica Carmosino

Department of Sciences, University of Basilicata

Via dell'Ateneo Lucano, Potenza (Italy)

Tel. +39-080-5443414, Fax +39-080-5443388, E-Mail monica.carmosino@unibas.it 
transfected cells surrounding a cell harboring the mutation. Furthermore, mCh-D243Gfs 4 HL-1 cardiomyocytes showed reduced CX43-dependent Lucifer Yellow (LY) loading and propagation. Of note, activation of $\beta$-catenin rescued both LY loading and LMNA D243Gfs*4 -HL-1 cells spontaneous activity propagation. Conclusion: Overall, the present results clearly indicate the involvement of the aberrant CX43 expression/activity as a pathogenic mechanism for the conduction defects associated to this LMNA truncating alteration.

(C) 2017 The Author(s)

Published by S. Karger AG, Basel

\section{Introduction}

Lamin A/C gene (LMNA) encodes two mammalian somatic cells polypeptides, Lamin A (664 amino acids) and Lamin C (574 amino acids), which are type V intermediate filaments comprising the $10 \mathrm{~nm}$ thick nuclear lamina on the inner aspect of the inner nuclear membrane. The Lamin A/C meshwork fulfill, with other proteins forming the nuclear lamina, a wide range of physiological functions such as organization and structure of nuclear membrane/ nuclear pore complexes/heterochromatin, DNA synthesis, responses to DNA damage, gene transcription, cell cycle progression, cell differentiation, cell migration and signal transduction regulation $[1,2]$. LMNA mutations result in a broad array of diseases, named laminopathies, the most common of which affects the heart in the form of dilated cardiomyopathy with conduction defects (DCM-CD) [3]. The clinical feature of DCM-CD is classically characterized by early conduction defects (e.g. sinus node dysfunction or atrioventricular conduction block), impaired systolic function and ventricular dilation, ultimately increasing the risk of sudden cardiac death and heart failure [1, 4]. However, in addition to DCM-CD, other forms of arrhythmogenic cardiomyopathies such as arrhythmogenic right ventricular cardiomyopathy (ARVC) have been linked to LMNA mutations [5].

Cardiac laminopathies result primarily from missense mutations (often in a dominant negative fashion), whilst truncating mutations resulting in Premature Termination Codon (PTC) are less common [6, 7]. In order to better exploring the functional effects of $L M N A$ truncating alterations associated to a cardiac phenotype, we recently studied a PTC mutation (R321X) upstream the LMNA Nuclear Localization Sequence (NLS) associated to severe cardiomyopathy [8]. At cellular level, the R321X mutant was found to accumulate within the endoplasmic reticulum (ER), likely unable to continue its biosynthetic pathway. This alteration also deeply impacts with the ability of this organelle to properly handle key physiological processes such as $\mathrm{Ca}^{2+}$ homeostasis, ER stress, and apoptosis [8].

Here, we studied another novel LMNA truncating alteration (c.728_747del,p.D243Gfs*4), identified in an Italian family showing a severe form of cardiomyopathy with poor prognosis. The mutation, here indicated as D243GFS*4, introduces a PTC within the 4th of 12 LMNA exons, thus producing a truncated isoform in the central a-helical coiled-coil rod domain (coil 2A) and missing the downstream NLS. When expressed in HEK293 or HL-1 cardiomyocytes cells, D243GFS*4 mislocalized within the ER, similarly with what we have previously shown in cells expressing R321X. Therefore, we supposed for the two truncated mutants of LMNA the same pathogenic cellular mechanism. However, ER mislocalization of D243GFS*4 did not significantly induce ER stress response and/or apoptosis when compared with cells expressing the wild type form of Lamin A. Although the expression of D243GFS*4 slightly albeit significantly reduced the ER $\mathrm{Ca}^{2+}$ levels, no abnormalities in cellular $\mathrm{Ca}^{2+}$ handling were recorded.

On the other hand, cells expressing D243GFS*4 showed a significant reduction of connexin43 (CX43) expression level and functional activity. Several groups have documented downregulation and/or abnormal localization and/or activity of connexins (known as gap junction remodeling) in experimental and human cardiomyopathies, including those induced by mutations in LMNA [9-11], which seems to predispose to cardiac conduction alterations. The expression of CX43 is modulated by diverse intracellular signaling pathways that can be impaired by the presence of $L M N A$ mutation [11]. Recently, Le Dour and collaborators showed that hearts of Lmna ${ }^{\mathrm{H} 222 \mathrm{P} / \mathrm{H} 222 \mathrm{P}}$ mice have reduced WNT and $\beta$-catenin expression levels, being 


\section{Cellular Physiology Cell Physiol Biochem 2017;44:1559-1577 \begin{tabular}{l|l|l}
\hline and Biochemistry 10.1159/000485651 & $\begin{array}{l}\text { C } 2017 \text { The Author(s). Published by S. Karger AG, Basel } \\
\text { www.karger.com/cpb }\end{array}$ \\
\hline
\end{tabular}

this latter less able to interact, on one hand, with the gene encoding CX43 to maintain its transcription and, on the other hand, with CX43 as part of a complex with the intercalated disc [9]. Here, we found that CX43 expression level and conduction defects were improved by drug-induced activation of the WNT/ $\beta$-catenin signaling pathway. However, cells expressing D243GFS*4 did not show neither reduction in $\beta$-catenin levels, as reported for Lmna ${ }^{\mathrm{H} 222 \mathrm{P} /}$ H222P, nor abnormalities in other signaling pathway involved in CX43 expression/function abnormalities, such as ERK 1/2 [12] or RhoA [13], likely indicating the presence of other intracellular CX43 modulators not yet identified.

\section{Materials and Methods}

\section{Patients}

The Lamin A p.D243Gfs*4 mutation was identified in a proband of an Italian family attending the outpatient hospital service dedicated to the diagnosis and management of cardiomyopathies at San CamilloForlanini hospital (Rome, Italy). All family members gave informed consent for the DNA analyses, which was approved by local ethic committees in accordance with the principles of the Declaration of Helsinki.

\section{Generation of the Lamin A constructs}

The frameshift nucleotide deletion LMNA-p.D243Gfs*4 was performed with Stratagene's Quik Change II XL site-directed mutagenesis kit (Agilent Technologies, Santa Clara, CA, USA), using the PCR product of LMNA cDNA cloned in the pcDNA ${ }^{\mathrm{Tm}} 6.2$ /N-EmGFP-DEST (Thermo Fisher Scientific, Waltham, MA, USA) vector system as a template [5, 8]. Mutagenic primers were designed using Quik Change Primer Design Program available online at www.agilent.com/genomics/qcpd/. The mutation was verified by sequencing. The synthetic gene mCherry $(\mathrm{mCh})$ was designed with $\mathrm{XbaI}$ and PspXI flanking restriction sites, inserted into pMA-RQ (ampR) and synthesized by Life technologies ${ }^{\mathrm{TM}}$ (Thermo Fisher Scientific, Waltham, MA, USA). The generation of Lamin A mCherry-tagged constructs was previously described [8].

\section{Cell culture and transient transfection}

HEK293 cell line was maintained in culture in DMEM high glucose, $2 \mathrm{mM} \mathrm{l-glutamine,} 10 \%$ foetal bovine serum, penicillin $(50 \mathrm{U} / \mathrm{ml})$ and streptomycin $(50 \mathrm{U} / \mathrm{ml})$ at $37^{\circ} \mathrm{C}, 5 \% \mathrm{CO} 2$ in a humidified incubator, and seeded for transfection. Cardiomyocytes HL-1 cell line is a generous gift of Prof. William Claycomb (LSU Health New Orleans, USA). They were maintained in culture and seeded for transfection as previously described [14]. HEK293 and HL-1 cells were transfected with either GFP- (or mCh) Lamin A- or GFP-(or $\mathrm{mCh})$ D243Gfs*4 constructs using Lipofectamine 2000 or Lipofectamine 3000 reagents, respectively, according to the manufacturer's instructions (Thermo Fisher Scientific, Waltham, MA, USA). For the analysis of $\mathrm{Ca}^{2+}$ dynamics in the ER, cells were transiently transfected with Cameleon D1ER [15].

\section{Protein extraction and Western blotting}

Where indicated, HEK293 cells were treated either with $100 \mu \mathrm{M}$ cyclopiazonic acid (CPA) for 5h or with $2 \mu \mathrm{M}$ Staurosporin (STP) for $6 \mathrm{~h}$ (all from Sigma-Aldrich, St. Louis, USA). For protein extraction from HEK293 cells transfected with the different Lamin A constructs we used RIPA buffer (150 mM NaCl, $10 \mathrm{mM}$ Tris $\mathrm{HCl}, 0.1 \%$ SDS, $1 \%$ Triton X-100, 1\% Na deoxycolate, $5 \mathrm{mM}$ EDTA) containing phosphatase inhibitors (10 mM NaF, $1 \mathrm{mM}$ sodium orthovanadate) and protease inhibitor cocktail (1:50; Roche, Basel, Switzerland) followed by sonication. Unsolubilized material was pelleted by centrifugation at $13,000 \times \mathrm{g}$ for $30 \mathrm{~min}$. at $4^{\circ} \mathrm{C}$. Extracted proteins were resolved using on $4-12 \%$ precast gel $(B o l t \circledast B$ BisTrisPlus gel; Thermo Fisher Scientific, Waltham, MA, USA or Mini-PROTEAN $®$ TGX Stain-Free ${ }^{\text {TM }}$ Precast Gels, Bio-Rad, Hercules, California, USA). Bands were electrophoretically transferred onto Immobilon-P membranes (Merck Millipore, Billerica, MA, USA) for Western blot analysis, blocked in TBS-Tween-20 containing 5\% BSA and incubated overnight with the following primary antibodies: anti-GFP (SC8334, dil. 1:200; Santa Cruz Biotechnology, Dallas, TX, USA) for both mutant and wild-type Lamin A detection, anti-CX43 (C6219, dil. 1:8000; Sigma-Aldrich, Saint Louis, MO, USA), anti-PARP (\#9542, dil. 1:2000, Cell Signaling Technology, Danvers, MA, USA) antiphospho-PERK (bs-3330R, dil. 1:500; Bioss Antibodies, Woburn, MA, USA), anti-phospho- $\beta$-Catenin (C4231, dil. 1:8000; Sigma-Aldrich, Saint Louis, MO, USA), anti-Rho A (sc418, dil. 1:500; Santa Cruz Biotechnology, 


\section{Cellular Physiology Cell Physiol Biochem 2017;44:1559-1577 and Biochemistry Published online: December 04, 2017 \begin{tabular}{l|l} 
DOI: 10.1159/000485651 & $\begin{array}{l}\text { C } 2017 \text { The Author(s). Published by S. Karger AG, Basel } \\
\text { www.karger.com/cpb }\end{array}$
\end{tabular} \\ Gerbino et al.: Truncating P.D243Gfs*4 LMNA Mutation and Cardiomyopathy}

Dallas, TX, USA), anti-phospho-Rho A (sc32954, dil. 1:500; Santa Cruz Biotechnology, Dallas, TX, USA), antiERK1/2 (051152, dil. 1:500; EMD Millipore, Billerica, MA, USA), anti-phospho-ERK1/2 (04797, 1:500; EMD Millipore, Billerica, MA, USA) and anti-GAPDH (MAB374 dil. 1:5000; EMD Millipore, Billerica, MA, USA). Immunoreactive bands were detected with secondary antibody conjugated to horseradish peroxidase (Tebu Bio, Le-Perray-en-Yvelines, France). The following day membranes were washed and incubated with horseradish peroxidase-conjugated secondary antibody. Negative control with secondary antibody alone was performed. The quantification of protein bands was performed by determination of the relative optical density using ImageJ software (National Institutes of Health, Bethesda, MD). Statistical analysis was performed on three independent experiments and significance calculated by Student's t-test for unpaired samples. Difference were considered significant at $\mathrm{P}<0.05$.

\section{Immunofluorescence confocal analysis}

For immunofluorescence confocal analysis, cells were grown on coverslips and $24 \mathrm{hr}$ after transfection were fixed and permeabilized in PFA with $0.1 \%$ Triton X-100 for $20 \mathrm{~min}$. at room temperature or methanol for $5 \mathrm{~min}$ at $4^{\circ} \mathrm{C}$. After washes with PBS, cells were blocked in saturation buffer $(1 \%$ bovine serum albumin in PBS) for $30 \mathrm{~min}$. at room temperature (RT) and incubated with the following antibodies: anti-Calnexin (sc6465, dil. 1:500; Santa Cruz Biotechnology, Dallas, TX, USA), anti-Nuclear Pore Complex (902901, dil. 1:500, San Diego, CA, USA ), anti-emerin (sc15378, dil. 1:200, Santa Cruz Biotechnology, Dallas, TX, USA ), anti-SERCA2 (sc8095, dil. 1:150; Santa Cruz Biotechnology, Dallas, TX, USA), anti-CX43 (C6219dil. 1:250; Sigma-Aldrich, Saint Louis, MO, USA), anti N-Cadherin (ab98952, dil. 1:500; Abcam, Cambridge, UK), for 2 hr at RT in blocking buffer. After three washes in PBS cells were incubated with 555 (or 488) Alexafluorconjugated secondary antibodies (Thermo Fisher Scientific, Waltham, MA, USA) for $1 \mathrm{hr}$ at RT. Confocal images were obtained with a confocal laser-scanning fluorescence microscope (Leica TSC-SP2, Mannheim, Germany).

Wherever needed, the collected confocal images (12-16 bit) where background subtracted and used for the quantitative evaluation of the fluorescence distribution from the plasma membrane to the cytosol along a fixed intensity line. The transfected cells of 15 different fields were analyzed with MetaMorph (Molecular Devices, MDS Analytical Technologies, Toronto, Canada) as imaging software. We calculated the mean pixel intensity as the average of values from at least 2 different transfected cells for each field. Statistical analysis was performed on three independent experiments and significance calculated by Student's t-test for unpaired samples. Difference were considered significant at $\mathrm{P}<0.05$.

\section{Evaluation of cytosolic and ER Ca ${ }^{2+}$ levels with either Fura-2 or FRET-based probe D1ER}

Steady state FRET experiments were performed as previously described [8]. Briefly, HEK293 cells seeded on poly-l-lysine-coated glass coverslips were transiently cotransfected with plasmids encoding either mCh-Lamin A or mCh-D243Gfs*4 and the FRET-based probe D1ER (gift from Prof. Roger Tsien) [15]. The experiments were carried out using MetaMorph (software from Molecular Devices, MDS Analytical Technologies, Toronto, Canada). CFP and citrine were excited at 435 or $509 \mathrm{~nm}$, respectively. FRET from CFP to citrine was determined by excitation of CFP and measurement of fluorescence emitted from citrine. FRET values were calculated as NetFRET according to the formula: NetFRET signal = FRET signal $-\mathrm{a} x$ YFP signal - $b$ x CFP signal, where $a$ and $b$ are the ratio of the signal in FRET channel to the signal in YFP channel in the absence of donor and to the signal in CFP channel in the absence of acceptor respectively. For statistical analysis, GraphPad Prism software (version 5.00, GraphPad Software, San Diego, California, USA) was used. Significant differences between means were tested by one-way analysis of variance (ANOVA) with NewmanKeuls's post-test. Significance was accepted for $\mathrm{p}$ values $<0.05$.

For intracellular $\mathrm{Ca}^{2+}$ measurements, mCh-Lamin A or mCh-D243Gfs*4-HEK293 cells were seeded on poly-L-lysine-coated glass coverslips (Ø $25 \mathrm{~mm}$ ). Ringer's Solution was used to perfuse cells during the experiment containing $140 \mathrm{mM} \mathrm{NaCl}, 5 \mathrm{mM} \mathrm{KCl}, 1 \mathrm{mM} \mathrm{MgCl} 2,10 \mathrm{mM}$ Hepes, $5 \mathrm{mM}$ Glucose, $1.0 \mathrm{mM}$ $\mathrm{CaCl} 2$, pH 7.4. HEK293 cells were stimulated with a variety of drugs as described in the results, including adenosine triphosphate (ATP), cyclopiazonic acid (CPA) and ionomycin (all from Sigma-Aldrich, SigmaAldrich, Saint Louis, MO, USA). mCh-Lamin A or mCh-D243Gfs*4-HEK293 cells were loaded with $5 \mu$ M Fura2 (Thermo Fisher Scientific, Waltham, MA, USA) for $25 \mathrm{~min}$ at $37^{\circ} \mathrm{C}$ in DMEM. Coverslips with dye-loaded cells were analysed with a set-up described in detail in previous papers of our group [16, 17]. Fluorescence measurements were performed using Metafluor (software from Molecular Devices, MDS Analytical 


\section{Cellular Physiology Cell Physiol Biochem 2017;44:1559-1577 \begin{tabular}{l|l} 
and Biochemistry Published onine: December 04, 2017 & $\begin{array}{l}\text { (c) } 2017 \text { The Author(s). Published by S. Karger AG, Basel } \\
\text { www.karger.com/cpb }\end{array}$
\end{tabular} \\ Gerbino et al.: Truncating P.D243Gfs*4 LMNA Mutation and Cardiomyopathy}

Technologies, Toronto, Canada). After background images correction, Fura 2 ratio was normalized to an average 2 min. baseline (R0) before agonist addition to obtain the relative unit R/R0.

Whenever needed intracellular $\mathrm{Ca}^{2+}$ concentration was determined as described by Grynkiewicz [18] according the following equation: $\left[\mathrm{Ca}^{2+}\right] \mathrm{i}=\mathrm{Kd}^{*} \mathrm{Q}(\mathrm{R}-\mathrm{Rmin}) /(\mathrm{Rmax}-\mathrm{R})$, where $\mathrm{Kd}(224 \mathrm{nM})$ indicated the dissociation constant of Fura-2AM for $\mathrm{Ca}^{2+} \mathrm{i}$ and $\mathrm{Q}$ indicated the ratio of the fluorescence intensities (F) at the minimum and the maximum $\mathrm{Ca}^{2+}$ concentration at $380 \mathrm{~nm}$. Each sample was calibrated by the addition of $5 \mu \mathrm{M}$ ionomycin in presence of $0.5 \mathrm{mM}$ EGTA (Rmin) followed by $5 \mu \mathrm{M}$ ionomycin in $10 \mathrm{mM} \mathrm{CaCl}_{2}$ (Rmax). The two independent traces in Fura-2 plots (e.g. mCh-Lamin A in dark grey and mCh-D243Gfs*4 in red) represent the means $\pm \mathrm{SE}$ at each time point of cells of the same coverslip. Statistical analysis was performed on at least 4 independent experiments for each group (e.g. mCh-Lamin A and mCh-D243Gfs*4) and significance calculated by Student's T-test for unpaired samples. Significance was accepted for $\mathrm{p}$ values $<0.05$.

The same imaging set-up and perfusion apparatus were used for the measurements of spontaneous intracellular $\mathrm{Ca}^{2+}$ oscillation in Hl-1 cells. Cells expressing either mCh-Lamin A or mCh-D243Gfs*4 were loaded with 2-4 $\mu$ M Fluo-4 (Thermo Fisher Scientific, Waltham, MA, USA) and excited at 488/20 every 150 milliseconds. Emitted fluorescence was passed through a dichroic mirror, filtered at $520 \mathrm{~nm}(\mathrm{Omega}$ Optical, Brattleboro, VT, USA). Fluo-4 is a non-ratiometric dye with a single excitation and a single emission wavelength, thus calibration of the recorded fluorescence intensities and determination of absolute $\mathrm{Ca}^{2+}$ concentration values in the cells is not ideal. In this work Fluo-4 fluorescence intensity values were normalized by the average of the first 8 diastolic values used as baseline (F0) to obtain a relative unit F/F0.

\section{Lucifer Yellow Uptake/Propagation Study}

HL-1 cells expressing either mCh-Lamin A or mCh-D243Gfs*4 in control conditions and after treatment with $20 \mathrm{mM}$ lithium chloride (o.n.) or $50 \mu \mathrm{M}$ lanthanum ( $45 \mathrm{~min}$ ) were incubated with $1 \mathrm{mM}$ Lucifer Yellow (LY) (Thermo Fisher Scientific, Waltham, MA, USA) for $45 \mathrm{~min}$ in normal culture medium. Unincorporated LY was removed, and cells were rinsed with phosphate-buffered saline. The fluorescence emitted by LY passed through a dicroic mirror (AT455DC, Chroma Technology Corp, Bellows Falls, VT, USA), filtered at 535/40m (AT535/40m, Chroma Technology Corp, Bellows Falls, VT, USA) and immediately evaluated by fluorescence microscopy using MetaMorph (software from Molecular Devices, MDS Analytical Technologies, Toronto, Canada) in 15 randomly selected fields with at least 5 transfected cardiomyocytes. For statistical analysis, GraphPad Prism software (version 5.00, GraphPad Software, San Diego, California, USA) was used. Significant differences between means were tested by one-way analysis of variance (ANOVA) with NewmanKeuls's post-test. Significance was accepted for $\mathrm{p}$ values $<0.05$.

\section{Results}

Clinical and genetics findings from an Italian family carrying D243Gfs*4 LMNA mutation

The proband, a 46 years old woman (case II:1, Fig. 1A), came to our attention because of presenting severe intraventricular cardiac conduction disorders (first and second degree Atrioventricular Block, LW AVB). Complex ventricular arrhythmias as Non-Sustained Ventricular Tachycardia (NSVT) and dual nodal reentrant Paroxysmal Supraventricular Tachycardia (PSVT) were also present. Ejection Fraction (EF) was 50\% and the patient was classified at first New York Heart Association (NYHA) class. Four years later, the cardiac manifestations worsened with symptoms of heart failure. The cardiac Nuclear Magnetic Resonance (MRI) detected the presence of patchy Late Gadolinium Enhancement (LGE) with a transmural pattern sections involving the basal, anterior and posterior septum of the inferior-mid wall. Echocardiographic analysis showed non dilated left ventricle with segmental akinesia (Fig. 1C). These signs were suggestive of inflammatory cardiomyopathy. The serum anti-heavy chain cardiac myosin and anti-intercalated heart disk antibodies resulted strongly positive. An automated Implantable Cardioverter Defibrillator (ICD) was then implanted, but, after nine months, the patient developed paroxysmal Atrial Fibrillation (AF) complicated by stroke. Later, an attempt of endomyocardial biopsy failed because of wall fissure and cardiac tamponade. The patient is currently stable, with a II class NYHA, $45 \% \mathrm{EF}$. 


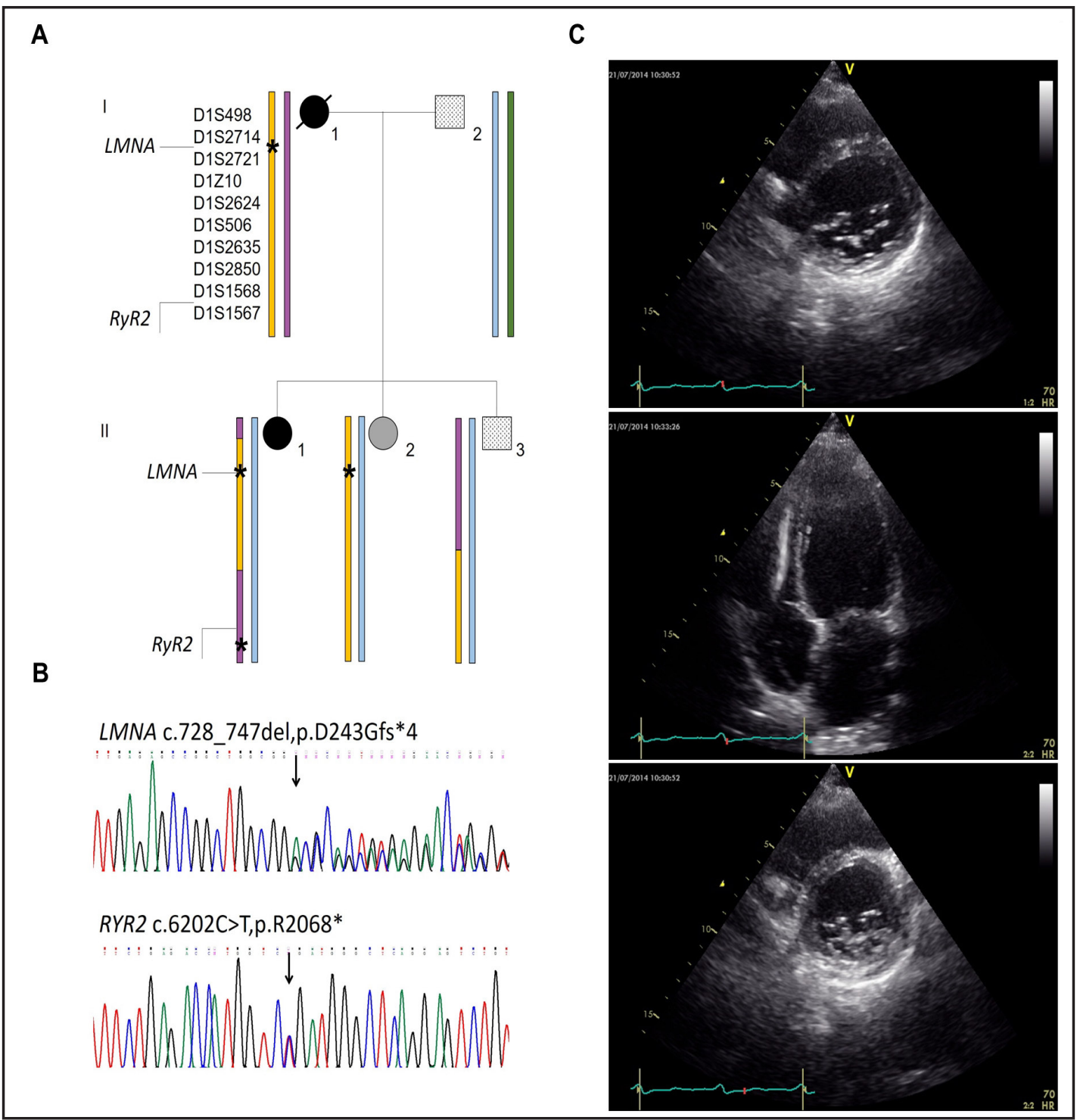

Fig. 1. Genetic characterization of the reported family. (A) Family pedigree. Individuals with cardiomyopathy and conduction defects are displayed as black symbols, the individual with conduction defects as a gray symbol, individuals with minor conduction defects as dotted symbols. The * mark stands for the LMNA and RYR2 mutations. Chromosome 1q22-1q43 together with the microsatellite markers employed for the segregation analysis and with the position of LMNA and RYR2 genes, are represented as vertical bars. Genomic DNA was not available for I:1, and consequently, for this patient, the presence of the LMNA mutation and the alleles of chromosome 1q22-1q43 markers were inferred. (B) Direct sequencing showing the presence of the heterozygous LMNA c.728_747del,p.D243Gfs*4 and RYR2 c.6202C>T,p.R2068*mutations in patient II:1. (C) Echocardiographic findings of patient II:1. A non dilated left ventricle with transmural LGE involving the basal segments of inferior and anterior septum were suggesting of inflammatory cardiomyopathy.

Physical examination revealed muscle strength deficit and recurrent pain at lower limbs, but CPK levels were normal in two dosages at rest. Muscle MRI could not be performed because of the implanted ICD. During genetic counseling, a family history of heart disease emerged: her mother, suffering by AF with a subsequent pacemaker (PMK) implantation, died at 60 years of stroke; her father was 71 years old and affected by bradycardia; her 45 years old sister presented first-degree AVB and episodic supraventricular and ventricular extrasystoles, while her brother was a 43 years-old smoker with isolated ventricular 


\section{Cellular Physiology Cell Physiol Biochem 2017;44:1559-1577

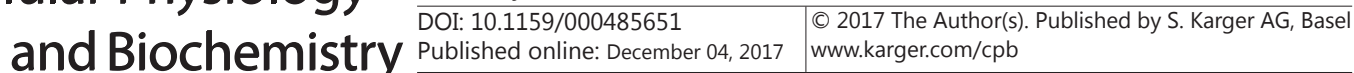 \\ Gerbino et al.: Truncating P.D243Gfs*4 LMNA Mutation and Cardiomyopathy}

extrasystoles. Both proband's siblings did not show any echocardiographic sign of structural abnormalities.

DNA was extracted from peripheral blood of cases I:2, II:1, II:2 and II:3. A panel of cardiomyopathy-related genes was tested in case II:1 by next generation sequencing as previously described [19]. Case II:1 was found to be double heterozygous for two non-synonymous rare (Minor Allele Frequency $=0$ ) genetic variants: the frameshift/truncating LMNA(NM_170707.2) c. 728 _ $747 \mathrm{~d} \mathrm{e} \mathrm{l,p.D} 243 \mathrm{G} \mathrm{f} \mathrm{s} * 4$ (chr1q22:156104680-156104699, hg19) and the nonsense RYR2(NM_001035.2) c.6202C>T,p.R2068* (chr1q43:237791142-237791142, hg19), which were confirmed by direct sequencing (Fig. 1B). The $L M N A$ variant was also found in case II:2, while cases I: 2 and II:3 did not

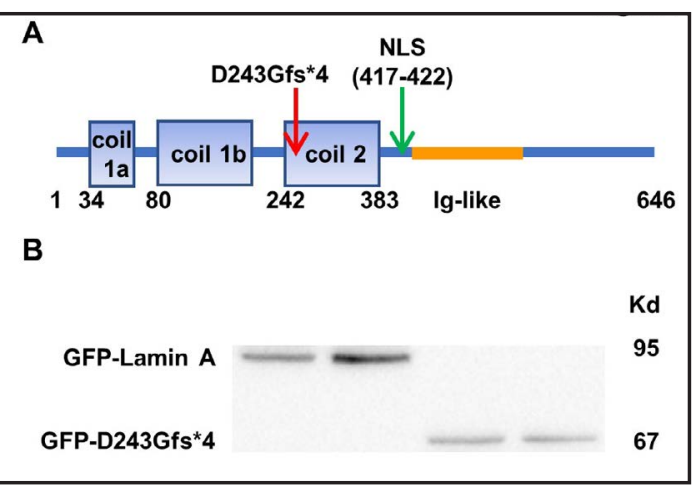

Fig. 2. Expression of GFP-D243Gfs*4 in HEK293 cells. (A) Localization of the nonsense mutation (D243Gfs*4) upstream of the nuclear localization sequence (NLS) on the Lamin A protein. (B) Lysates from HEK 293 cells expressing either GFP-Lamin A or GFP-D243Gfs*4 were subjected to Western blot analysis using a monoclonal antibody raised against GFP. carry neither the LMNA nor the RYR2 mutation. Familial chromosome 1q22-1q43 analysis by ten different microsatellite markers (i.e. D1S498, D1S2714, D1S2721, D1Z10, D1S2624, D1S506, D1S2635, D1S2850, D1S1568 and D1S1567) showed that the LMNA mutation segregates in the two daughters from the same maternal allele, while, in the proband, the RYR2 variant could be either de novo or inherited on the other maternal chromosome. The microsatellite segregation as well as mutation-specific PCR, excluded the hypothesis of paternal mosaicism in leukocytes for both LMNA and RYR2 alterations.

Since the LMNA D243Gfs*4 has been found in both the proband and her sister, we believe that this mutation is the major genetic determinant for the cardiac phenotype of this form of familiar cardiomyopathy. Therefore, we focused our attention on the functional characterization of this Lamin A variant.

\section{Expression of D243Gfs*4 mutant in HEK293 cells}

The LMNA D243Gfs*4 mutation was found to introduces a premature termination codon, upstream the NLS, thus producing a truncated protein isoform in the coil2a of Lamin A (Fig. 2A). Here, GFP-tagged Lamin A wild-type (GFP-Lamin A) and D243Gfs*4 (GFPD243Gfs*4) were transiently expressed in HEK293 cells and identified by Western blotting using an anti-GFP antibody. Fig. 2B shows two immunoreactive bands of approximately 95 and $67 \mathrm{kD}$ corresponding to the wild-type ( $68 \mathrm{kD}$ for Lamin A plus $27 \mathrm{kD}$ for GFP) and the truncated protein (40 kD for D243Gfs*4 plus $27 \mathrm{kD}$ for GFP), respectively. Image analysis by laser-scanning confocal microscopy showed that mCherry-tagged D243Gfs*4 (mChD243Gfs*4) was mainly localized in a cytoplasmatic vesicular compartment when compared to mCherry-tagged Lamin A (mCh-Lamin A), which was selectively expressed along the nuclear rim (Fig. 3A). Colocalization of both mCh-Lamin A and mCh-D243Gfs*4 with the ER marker calnexin supports the conclusion that most of D243Gfs*4 is localized within the ER and outside the nucleoplasm. Of note, the expression of mCh-D243Gfs*4 into the ER did not alter the localization of other nuclear envelope proteins such as emerin (Fig. 3B), as showed for other truncating LMNA mutations [20]. Since both the D243Gfs*4 and the previously studied R321X [8] share the same peculiar ER localization, we supposed for these truncating mutations common pathogenic mechanisms once transfected in HEK293 cells.

Expression of D243Gfs*4: ER stress and apoptosis

At first, we evaluated whether the inappropriate localization and putative accumulation of a truncated protein, D243Gfs*4, into the ER might induce the Unfolded Protein Response 


\section{Cellular Physiology and Biochemistry}

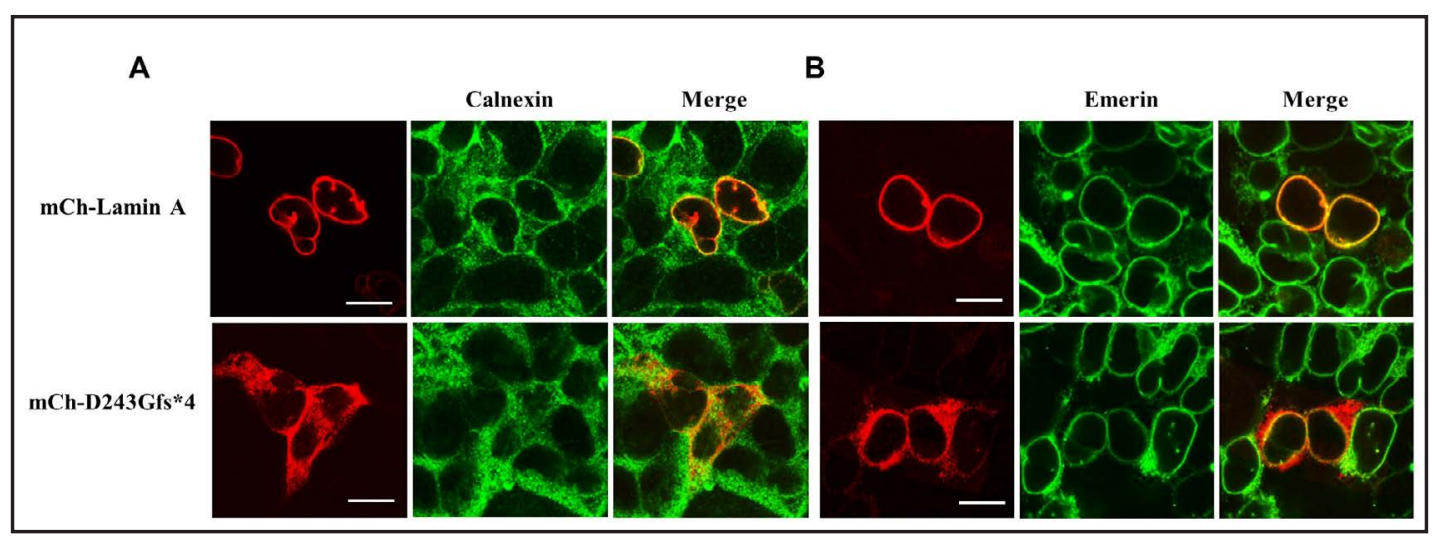

Fig. 3. Localization of mCh-D243Gfs*4 in HEK293 cells. HEK293 cells were transfected with either mChLamin A (upper panels) or mCh-D243Gfs*4 (lower panels) and analysed after $24 \mathrm{hr}$ by confocal laserscanning microscopy using a polyclonal anti-calnexin (A) antibody as ER marker or emerin (B) antibody. Colocalization is shown in yellow in the Merge panels. Scale bars $=5 \mu \mathrm{m}$.

(UPR), as we recently showed for R321X [8]. Thus, we followed the phosphorylation of PERK, a kinase localized on the ER membrane, which phosphorylates eIF2 leading to the expression of GADD153 (CHOP) which in turns leads to the expression of proapoptotic genes [21]. The expression of phosphorylated PERK (p-PERK) was evaluated by Western blotting (Fig. 4A) in cells transfected with either GFP-Lamin A or GFP-D243Gfs*4 in control conditions (e.g. in the absence of any further ER stress-inducing manoeuvre). As shown in Fig. 4A, the expression of GFP-D243Gfs*4 by itself did not significantly increase the expression of p-PERK when compared with cells expressing GFP-Lamin A. As positive control we used an experimental maneuver known to induce ER stress such as pretreatment with cyclopiazonic acid (CPA, 100 $\mu \mathrm{M}$ for $5 \mathrm{~h}$ ), a well known inhibitor of the sarco-endoplasmic reticulum $\mathrm{Ca}^{2+}$-ATPase (SERCA) pump [22]. These data suggest that the expression of GFP-D243Gfs*4 is not able, per se, to induce phosphorylation of PERK and thus ER stress.

Next, we measured the rate of cell apoptosis in either GFP-Lamin A or GFP-D243Gfs*4 by directly evaluating caspases activation which, in turn, initiate programmed cell death by cleaving/activating effectors such as the Poly (ADP-ribose) polymerase (PARP) [23]. Once cleaved, an $85 \mathrm{kD}$ fragment was excited from the $116 \mathrm{kD}$ intact PARP molecule. As shown in Fig. 4B, in GFP-D243Gfs*4-expressing cells, the product of caspases-dependent PARP cleavage ( $85 \mathrm{kD}$ band) was barely detectable compared to the full length uncleaved PARP molecule, indicating the absence of apoptosis in these cells compared to GFP-Lamin A-expressing cells. As positive control, cells were treated with Staurosporin (STP), known to induce caspase-dependent apoptosis and consequent PARP cleavage [24] (Fig. 4B, + STP).

\section{ER expression of D243Gfs* 4 does not affect the overall cellular $\mathrm{Ca}^{2+}$ dynamics}

To verify whether the observed ER accumulation of D243Gfs*4 was in turn influencing the proper functionality of the ER, we measured intraluminal ER $\mathrm{Ca}^{2+}$ levels with the FRETbased probe D1ER, in cells transfected with either mCh-Lamin A or mCh-D243Gfs*4. Steadystate FRET experiments showed that ER $\mathrm{Ca}^{2+}$ levels measured as NetFRET were significantly reduced in cells expressing $\mathrm{mCh}-\mathrm{D} 243 \mathrm{Gfs} * 4$ when compared with cells expressing the mChLamin A (Fig. 5A). We therefore evaluated whether this small reduction in steady-state ER $\mathrm{Ca}^{2+}$ levels induced by D243Gfs*4 expression causes impairment of cytosolic $\mathrm{Ca}^{2+}$ handling. As shown in Fig. 5B, no differences in the resting $\left[\mathrm{Ca}^{2+}\right]_{\mathrm{cyt}}$ were observed between mChD243Gfs*4- and mCh-Lamin A-transfected cells loaded with Fura-2 AM.

We also evaluated if the expression of mCh-D243Gfs*4 might impair the response to physiological $\mathrm{Ca}^{2+}$-mediated agonists such as ATP $100 \mu \mathrm{M}$. Fig. 5C shows that in HEK 293 cells expressing mCh-D243Gfs*4 the perfusion with ATP was able to induce a transient increase in Fura- 2 ratio that resulted unchanged when compared with cells expressing mCh-Lamin A. In

\section{KARGER}




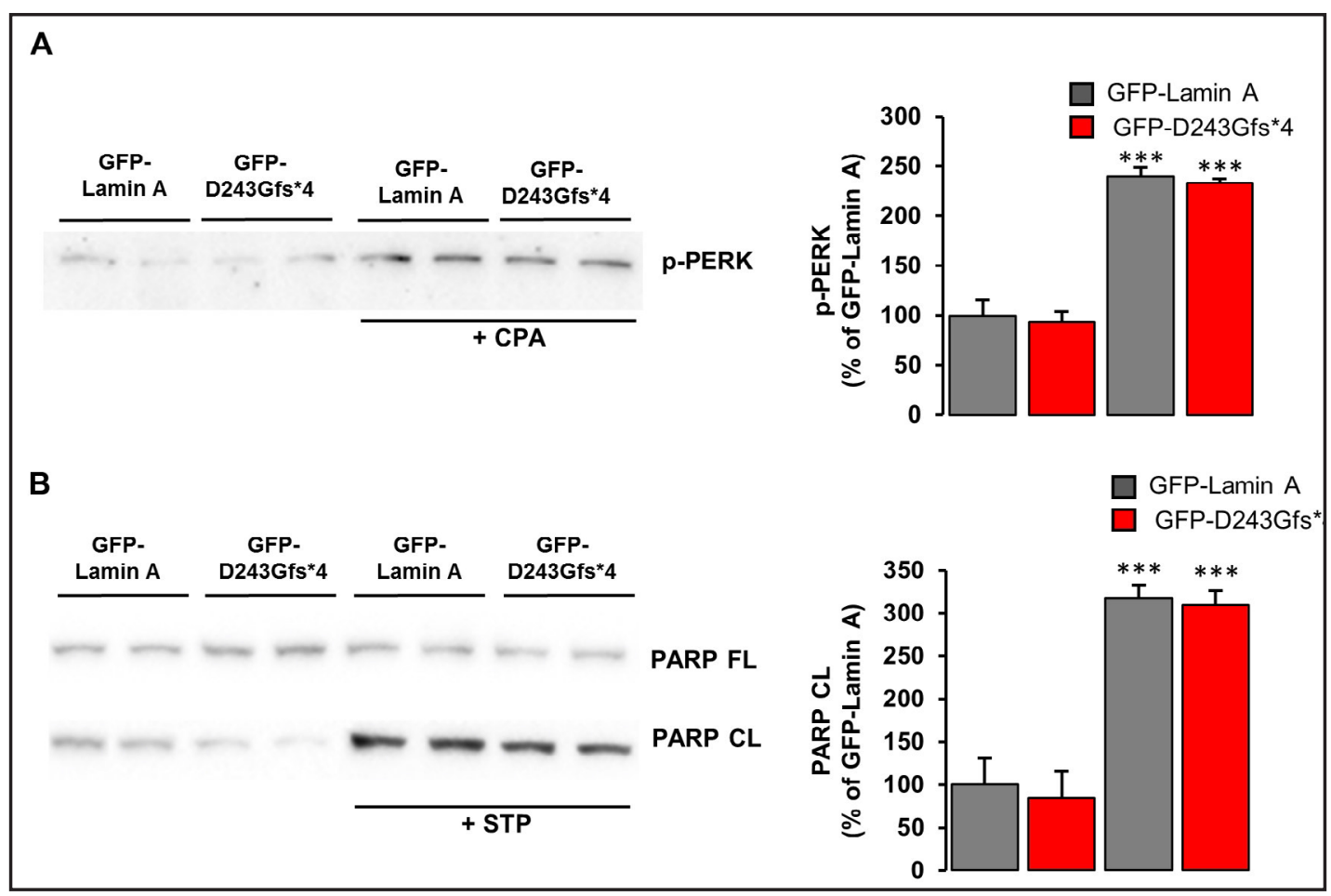

Fig. 4. Effect of the expression of GFP- D243Gfs*4 on ER stress and apoptosis. (A) HEK293 cells expressing either GFP-Lamin A or GFP-D243Gfs*4 were treated or not with $100 \mu \mathrm{M}$ CPA for 5h, lysed and subjected to Western blot analysis to detect the phosphorylation of PERK (p-PERK) normalized to total protein level on stain-free gel (p-PERK: Lamin A: $100 \pm 15.30$; D243Gfs*4: $93 \pm 10.57$, Lamin A+CPA: $240 \pm 8.78$; D243Gfs*4+CPA: $233 \pm 3.74 ;{ }^{* * *} \mathrm{P}<0.001$ vs Lamin A). (B) HEK293 cells expressing either GFP-Lamin A or GFP-D243Gfs*4 were treated or not with $2 \mu \mathrm{M}$ STP for $6 \mathrm{~h}$, lysed and subjected to Western blot analysis to detect the expression of either full length- or cleaved PARP (PARP FL and PARP CL respectively), normalized to total protein level on stain-free gel, as markers of caspase activity and thus apoptosis (PARP CL; Lamin A: $100 \pm 30.88$; D243Gfs*4: $84 \pm 31.03$, Lamin A+CPA: $317 \pm 15.62$; D243Gfs*4+CPA: $310 \pm 16.95 ;{ }^{* * *} \mathrm{P}<0.001$ vs Lamin A), Data are presented as \% of GFP-Lamin A expressing cells.

separate experiments, cells were treated with the SERCA blocker cyclopiazonic acid $(20 \mu \mathrm{M}$ CPA) while perfused with $\mathrm{Ca}^{2+}$-free medium (Fig. 5D). This procedure first evoked a transient increase in Fura-2 Ratio due to release of $\mathrm{Ca}^{2+}$ from the stores. Despite the lower $\mathrm{ER} \mathrm{Ca}^{2+}$ levels in mCh-D243Gfs*4-expressing cells, CPA-induced ER $\mathrm{Ca}^{2+}$ release was not significantly different when compared with cells expressing the mCh-Lamin A. When the release of stored $\mathrm{Ca}^{2+}$ reached a plateau, the addition of ATP induced a second and maximal release of $\mathrm{Ca}^{2+}$ from the ER, which equals the maximal amount of free $\mathrm{Ca}^{2+}$ releasable from the store. Still, we did not find difference in cells harboring the mutation compared to wild type ones. After complete store emptying, $2 \mathrm{mM} \mathrm{Ca}^{2+}$ was re-added to the medium in the continuous presence of CPA. This maneuver evoked a third increase in Fura-2 ratio via capacitative $\mathrm{Ca}^{2+}$ entry at the plasma membrane, which was identical in mCh-D243Gfs* 4 and mCh-Lamin A transfected cells.

Thus, although the expression of D243Gfs*4 slightly albeit significantly reduced the $\mathrm{ER} \mathrm{Ca}^{2+}$ levels, nor abnormalities in cytosolic $\mathrm{Ca}^{2+}$ levels neither in response to $\mathrm{Ca}^{2+}$ mediated agonists or ER $\mathrm{Ca}^{2+}$ emptying maneuver were recorded in FRET and video-imaging experiments, respectively.

Altered CX43 expression in HEK293 cells expressing GFP-D243Gfs*4

Because of the cardiac conduction abnormalities that occur in patients carrying D243Gfs*4, we examined the expression of CX43 a key protein component of myocardial 


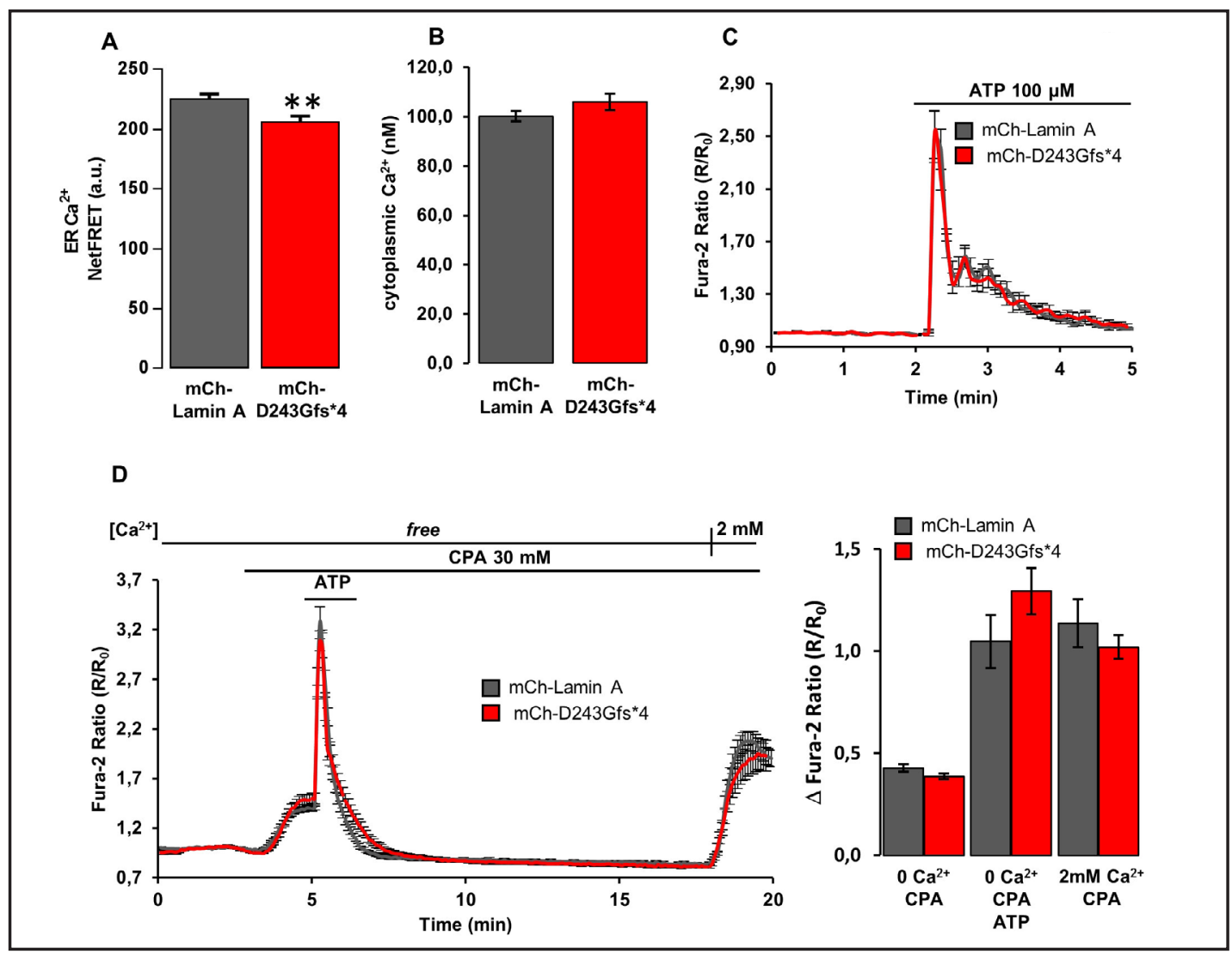

Fig. 5. The reduction of ER $\mathrm{Ca}^{2+}$ levels induced by expression of $\mathrm{D} 243 \mathrm{Gfs} * 4$ is not caused by changes in $\left[\mathrm{Ca}^{2+}\right]_{\text {cyt }}$ and does not impair $\mathrm{Ca}^{2+}$ handling. (A) The histogram shows the steady-state D1ER netFRET signal (a.u.) of HEK293 cells expressing either mCh-Lamin A (grey bar, $\mathrm{n}=74$ cells) or mCh- D243Gfs*4 (red bar, $\mathrm{n}=72$ cells). Data are expressed as means \pm S.E.. Statistical analysis was performed on three independent experiments and significance calculated by ANOVA. ${ }^{*} \mathrm{P}<0.01$ versus mCh-Lamin A. (B) HEK293 cells expressing either mCh-Lamin A (grey bar) or mCh- D243Gfs*4 (red bar) were loaded with Fura-2 and the free cytosolic $\left[\mathrm{Ca}^{2+}\right]$ cyt was calculated as described in the Methods. Data are expressed as mean \pm S.E. Statistical analysis was performed on three independent experiments and significance calculated by Student's t-test for unpaired samples. P = n.s. (C) Fura-2 loaded HEK293 cells expressing either mCh-Lamin A (gray trace) or mCh-D243Gfs*4 (red trace) were challenged with the $\mathrm{Ca}^{2+}$-mediated agonist ATP. Data are expressed as mean \pm S.E. of cells of the same coverslip. (D) Time course of changes of Fura 2 Ratio before, during, and after application of $20 \mu \mathrm{M}$ CPA in the absence $\left(0 \mathrm{Ca}^{2+}\right)$ or presence of extracellular $\mathrm{Ca}^{2+}(2.0 \mathrm{mM})$ and ATP in Fura-2 loaded HEK293 cells expressing either mCh-Lamin A (grey trace) or mCh-D243Gfs*4 (red trace). (E) Summarized data of the amplitude of $\mathrm{CPA}$-induced $\mathrm{Ca}^{2+}$ release in the absence of extracellular $\mathrm{Ca}^{2+}$, after addition of ATP, and activation of CPA-induced capacitative $\mathrm{Ca}^{2+}$ entry. mCh-Lamin A, grey bars; mCh-D243Gfs*4, red bars. Data are expressed as mean \pm S.E. Statistical analysis was performed on three independent experiments and significance calculated by Student's t-test for unpaired samples. $\mathrm{P}=\mathrm{n} . \mathrm{s}$ versus mCh-Lamin A.

gap junction endogenously expressed by HEK293 cells [25]. We observed decreased CX43 expression by Western Blotting analysis in HEK-GFP-D243Gfs*4 cells compared to HEKGFP-Lamin A cells (Fig. 6A). In addition, the significant reduction of CX43 expression level in HEK293-D243Gfs*4 cells was significantly rescued by activation of the WNT/ $\beta$-catenin signaling pathway with lithium (Fig. 6B), a non-selective inhibitor of GSK3- $\beta$ whose activity leads to $\beta$-catenin degradation by the proteasome. Thus, we evaluated weather the observed down-regulation of CX43 was a consequence of the reduced activity of WNT/ $\beta$-catenin pathway, as reported recently by Le Dour and colleagues [9]. However, we did not find 


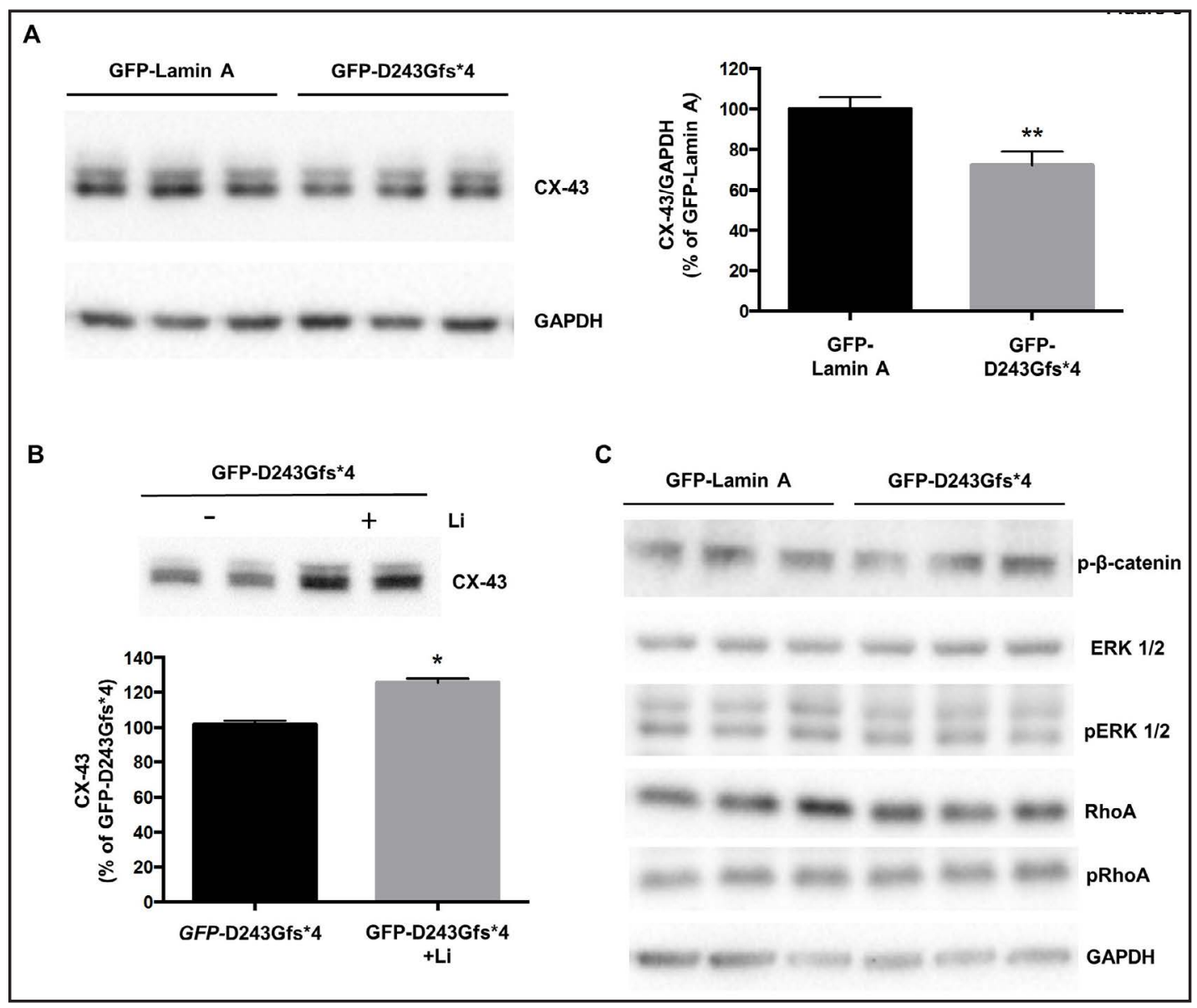

Fig. 6. Effect of the expression of GFP-D243Gfs*4 on CX43. (A) HEK 293 cells expressing either GFP-Lamin A or GFP-D243Gfs*4 were lysed and subjected to Western blot analysis to detect the expression level of CX43. The statistical analysis graph of relative expression levels of p-PERK was normalized to that of GAPDH. Statistical analysis was performed on three independent experiments and significance calculated by Student's t-test for unpaired samples (CX43/GAPDH; Lamin A: $100 \pm 5.7$ versus D243Gfs*4: 72.11 \pm 6.83, ** $\mathrm{P}<0.01$ ). (B) HEK 293 cells expressing either GFP-Lamin A or GFP- D243Gfs*4 were lysed and subjected to Western blot analysis to detect the expression level of CX43 after overnight pretreatment with Lithium Chloride $20 \mathrm{mM}$. The statistical analysis graph of relative expression levels of CX43 was normalized to total protein level on stain-free gel. Statistical analysis was performed on three independent experiments and significance calculated by Student's t-test for unpaired samples (CX43 level; GFP-D243Gfs*4: $100 \pm 2.28$ versus GFP-D243Gfs*4+Li: 125.7 $\pm 2.13, *$ P<0.05). (C) HEK 293 cells expressing either GFP-Lamin A or GFPD243Gfs*4 were lysed and subjected to Western blot analysis to detect the expression level of phospho- $\beta$ catenin, ERK 1/2, p-ERK1/2, RhoA and p-RhoA. The statistical analysis graph of relative expression levels of each protein was normalized to that of GAPDH. Statistical analysis was performed on three independent experiments and significance calculated by Student's t-test for unpaired samples (phospho- $\beta$-catenin / GAPDH; Lamin A: $0.627 \pm 0.09$ versus D243Gfs*4: 0.676 \pm 0.10, P = n.s; ERK 1/2/GAPDH; Lamin A: 2.175 \pm 0.36 versus D243Gfs*4: $2.26 \pm 0.17$, P = n.s; p-ERK1/2/GAPDH; Lamin A: $2.712 \pm 0.6$ versus D243Gfs*4: $2.498 \pm 0.317$, P = n.s; RhoA/GAPDH; Lamin A: $1.356 \pm 0.16$ versus D243Gfs*4: $1.621 \pm 0.15, P=$ n.s; p-RhoA /GAPDH; Lamin A: $3.117 \pm 0.5$ versus D243Gfs*4: $3.092 \pm 0.2, \mathrm{P}=\mathrm{n} . \mathrm{s})$.

neither reduction in phospho $\beta$-catenin levels (Fig. $6 \mathrm{C}$, p- $\beta$-catenin) nor abnormalities in other signaling pathways involved in CX43 expression/function regulation, such as ERK $1 / 2$ [26] (Fig. 6C) or RhoA [13] (Fig. 6C). The RhoA/p-RhoA and ERK 1/2 /p-ERK1/2 ratios were not statistically different in the two cell lysates (data not shown).

\section{KARGER}




\section{\begin{tabular}{ll} 
Cellular Physiology & Cell Physiol Biochem 2017;44:1559-1577 \\
\hline DOI: 10.1159/000485651 & | 2017 The Author(s). Published by S. Karger AG, Basel
\end{tabular}

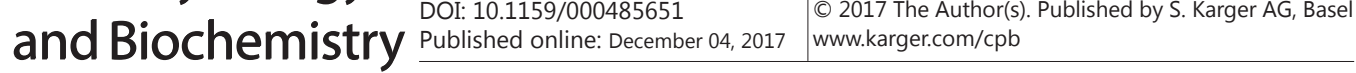 Gerbino et al.: Truncating P.D243Gfs*4 LMNA Mutation and Cardiomyopathy}

Localization and functional characterization of D243Gfs*4 mutant in HL-1 cardiomyocytes

Next, we evaluated the expression of the D243Gfs*4 in HL-1 cardiomyocytes. Image analysis by laser-scanning confocal microscopy confirmed also in HL-1 cardiomyocytes that mCh-D243Gfs*4 was mainly localized in a cytoplasmatic vesicular compartment when compared to mCh-Lamin A, which was selectively expressed along the nuclear rim (Fig. 7A, WT). Colocalization of both mCh-Lamin A and mCh-D243Gfs*4 with the cardiac ER marker SERCA-2 supports the conclusion that most of D243Gfs*4 is localized within the ER (5A, D243Gfs*4). The mislocalization of mCh-D243Gfs*4 into the ER did not alter the localization of other nuclear envelope proteins such as emerin (Fig. 7B) and nuclear pores (Fig. 7C). In addition, we observed a reduced expression of CX43 in juxtaposed areas of the plasma membranes between HL-1 cells expressing mCh-D243Gfs*4 and others not transfected (Fig. 8A). The fluorescence profiles indicating line intensity in the representative images of figure 8A show peaks at the plasma membrane and in its close proximity when compared to the cytosol. Quantitatively, the summary of fluorescence intensity of CX43 at the plasma membrane of HL-1 cells expressing mCh-D243Gfs*4 was significantly lower than the analogous parameter in HL-1 expressing mCh-Lamin A.

Interestingly, when we investigated the possible modulation of another component of the intercalated disks, such as $\mathrm{N}$-Cadherin, we found that neither its expression nor its localization were affected by the expression of mCh-D243Gfs*4 in HL-1 cells (Fig. 8B).

To evaluate whether HL-1 cardiomyocytes were affected by abnormalities related to the reduced expression of CX43 we studied the spontaneous $\mathrm{Ca}^{2+}$ oscillations recorded in these cells as result of propagation of the depolarizing waves through the gap junctions. The electrical activity of cardiomyocytes creating a functional syncytium is synchronized and driven by the cells that have the fastest frequency of generation of spontaneous action potentials. Under this scenario, electrical coupling by gap junctions is the key determinant of conduction velocities in HL-1 cardiomyocytes [27]. In fact, when we recorded the spontaneous $\mathrm{Ca}^{2+}$ oscillations in 4 cells of the same functional syncytium we found the same pattern of

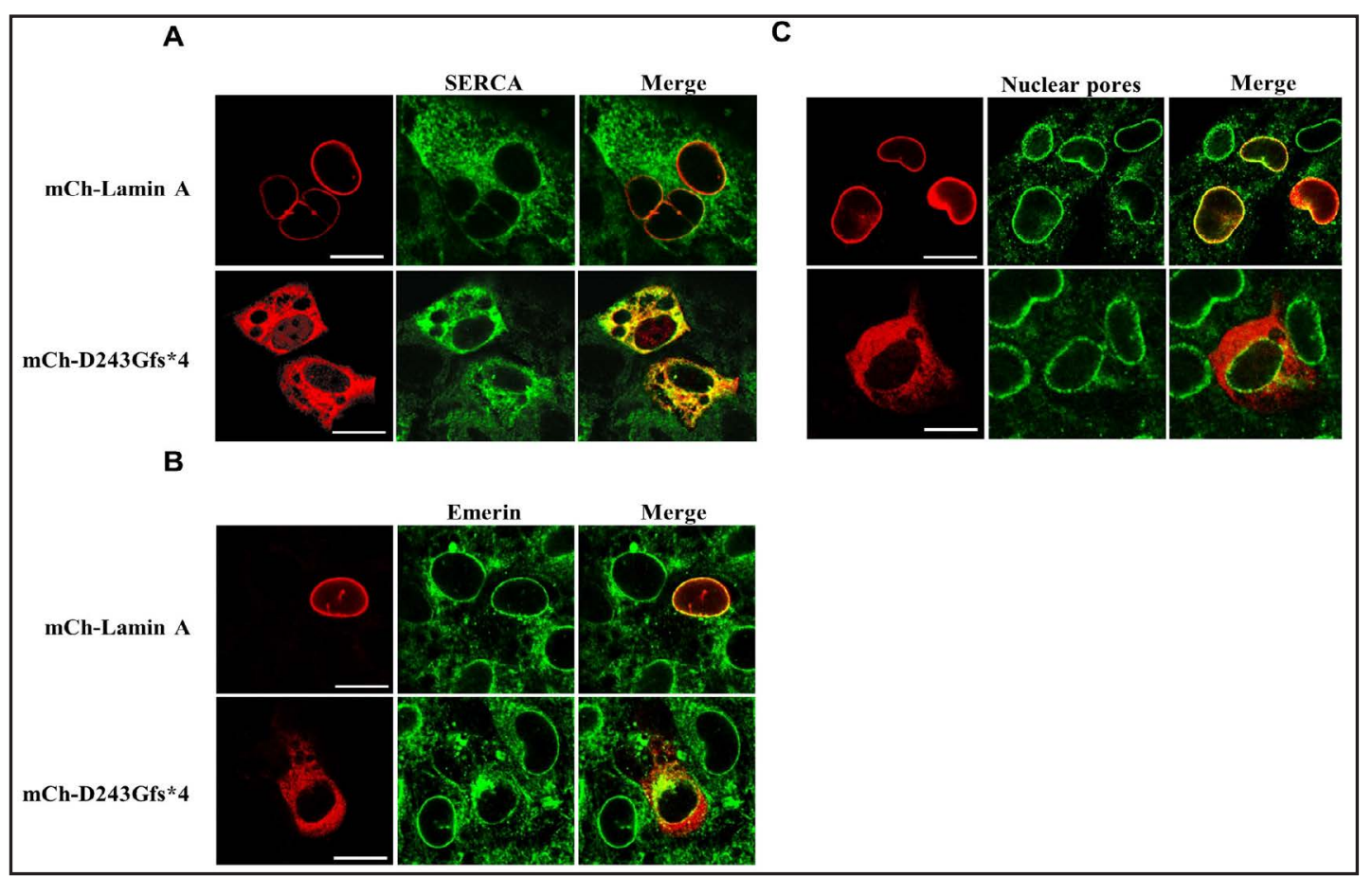

Fig. 7. Localization of mCh-D243Gfs*4 in HL-1 cardiomyocytes. HL-1 cells were transfected with either mCh-Lamin A (upper panels) or mCh-D243Gfs*4 (lower panels) and analyzed after 24 hr by confocal laserscanning microscopy using a polyclonal anti-SERCA antibody as ER marker (A), Emerin (B) and nuclear pores (C) as nuclear markers. Scale bars $=8 \mu \mathrm{m}$. 


\section{Cellular Physiology Cell Physiol Biochem 2017;44:1559-1577

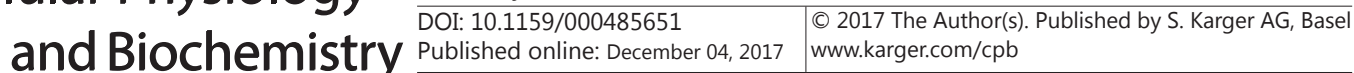 Gerbino et al.: Truncating P.D243Gfs*4 LMNA Mutation and Cardiomyopathy}

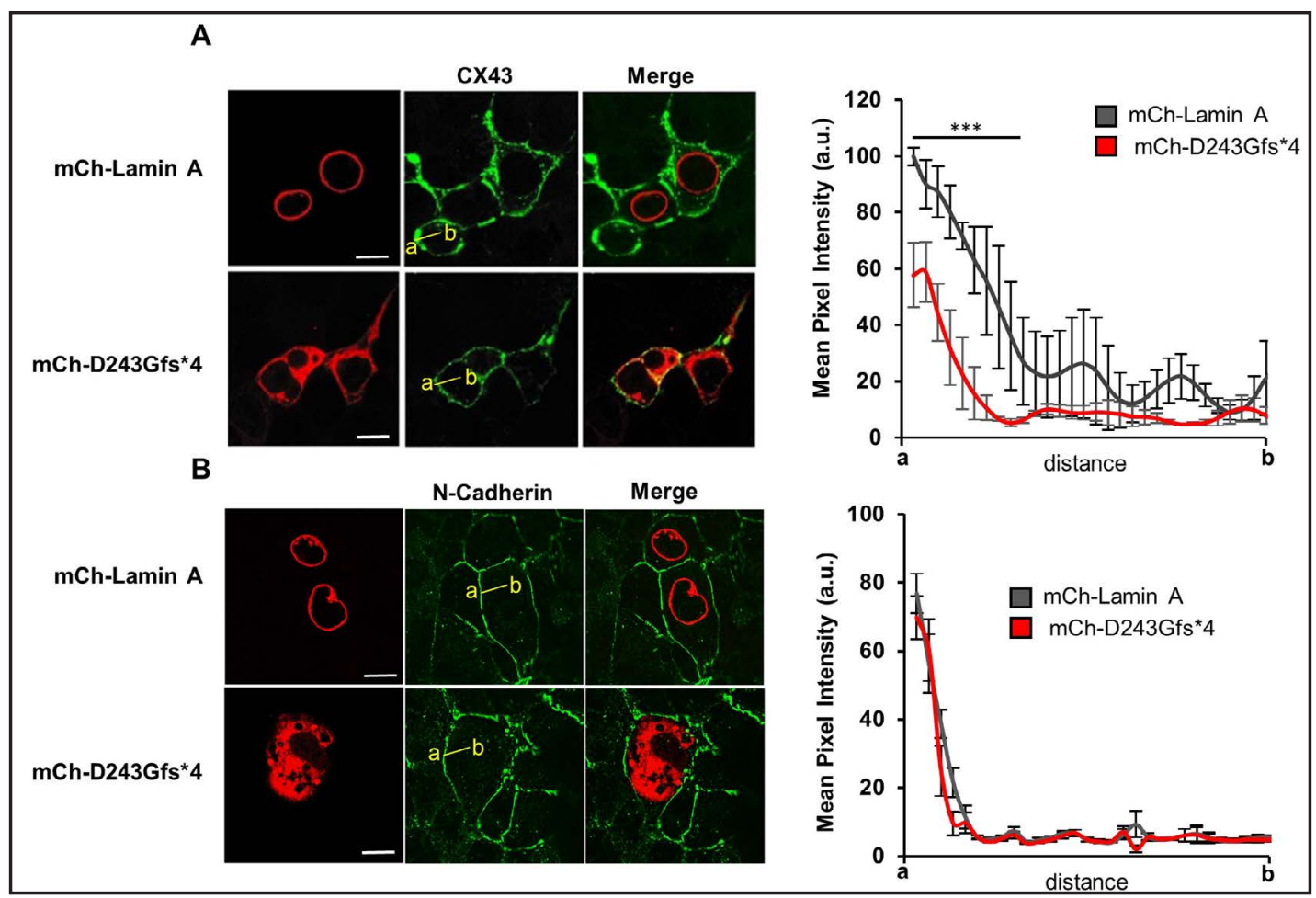

Fig. 8. Localization and expression of CX43 and N-Cadherin in HL-1 cardiomyocytes. HL-1 cells were transfected with either mCh-Lamin A (upper panels) or mCh-D243Gfs*4 (lower panels) and analyzed after $24 \mathrm{hr}$ by confocal laser-scanning microscopy using anti CX43 antibody (A) and anti N-Cadherin antibody (B). Colocalization is shown in yellow in the merge panels (Scale bars: $8 \mu \mathrm{m}$ ). The quantitative analysis of CX43 or N-Cadherin plasma membrane /cytosol fluorescence distribution along a fixed yellow line (from a to b) was performed in at least two transfected cells of 15 different fields using MetaMorph as imaging software. The mean pixel intensity is the average of values from different transfected cells. For CX43, mCh-D243Gfs* $\mathrm{n}=37$ cells vs $\mathrm{mCh}$-Lamin A $\mathrm{n}=42$ cells; for $\mathrm{N}$-Chaderin, mCh-D243Gfs* $\mathrm{n}=35$ cells vs mCh-Lamin A $n=39$ cells. Statistical analysis was performed on three independent experiments and significance calculated by Student's t-test for unpaired samples. ${ }^{* * *} \mathrm{P}<0.001$ vs Lamin A.

$\mathrm{Ca}^{2+}$ oscillations between a cell expressing $\mathrm{mCh}$-Lamin A (identified by the red fluorescence) and the three cells in close proximity (Fig. 9A). On the other hand, Fluo-4 loaded HL-1 transfected with mCh-D243Gfs*4 showed irregular spontaneous oscillations of intracellular $\mathrm{Ca}^{2+}$ levels (Fig. 9B, *). Of note, the same pattern of irregular $\mathrm{Ca}^{2+}$ oscillations was recorded in the cardiomyocyte directly coupled with the cell expressing mCh-D243Gfs*4 (Fig. 9B, 1). A significant rescue of a more regular phenotype was recorded in cardiomyocytes in the close proximity (Fig. 9B, 2, 3) but not directly coupled with the cell carrying the mutation. These evidences are in line with a conduction defects probably related with the expression of gap junction.

Indeed, when we evaluated the specific amount of functional CX43 with the Lucifer Yellow (LY) loading (Fig. 10A), we found a significant reduction in the amount of LY fluorescence in HL-1 expressing mCh-D243Gfs*4 when compared with cells expressing mCh-Lamin A. The non-selective binding of LY was determined in the presence of a connexin hemichannel blocker, $50 \mu \mathrm{M}$ Lanthanum, which was added 55 min prior to LY (data not shown). Of note, treatment with lithium chloride (20 mM for 24 hours) completely rescued the amount of LY loaded in mCh-D243Gfs*4-HL-1 cells when compared to cells expressing mCh-Lamin A. In addition, when we evaluated the effect of lithium on the spontaneous intracellular $\mathrm{Ca}^{2+}$ oscillationas, we found a more regular pattern in both the cell carrying the mutation (Fig. 10B, *) and others not transfected (Fig. 10B, 1, 2,3).

\section{KARGER}




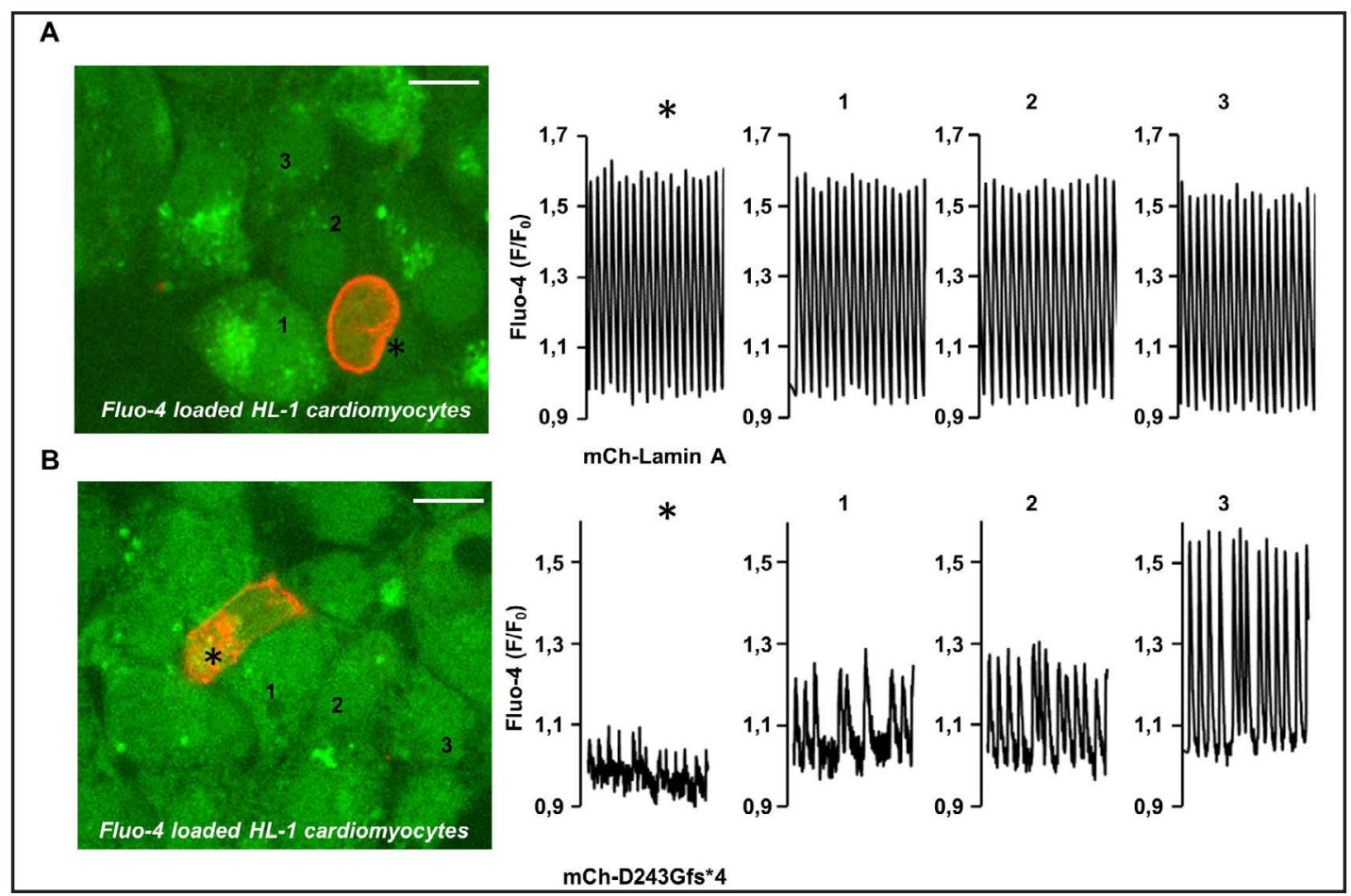

Fig. 9. Effect of the expression of mCh-D243Gfs*4 on spontaneous $\mathrm{Ca}^{2+}$ oscillation in HL-1 cardiomyocytes. HL-1 cells were transfected with either mCh-Lamin A (A) or mCh-D243Gfs*4 (B) and loaded with Fluo4. The spontaneous oscillation of four continuous cells were recorded. * indicates transfected HL-1 cells (either with mCh-Lamin A or mCh-D243Gfs*4). 1,2,3 indicate continuous HL-1 cells not transfected. Scale bars: $8 \mu \mathrm{m}$.

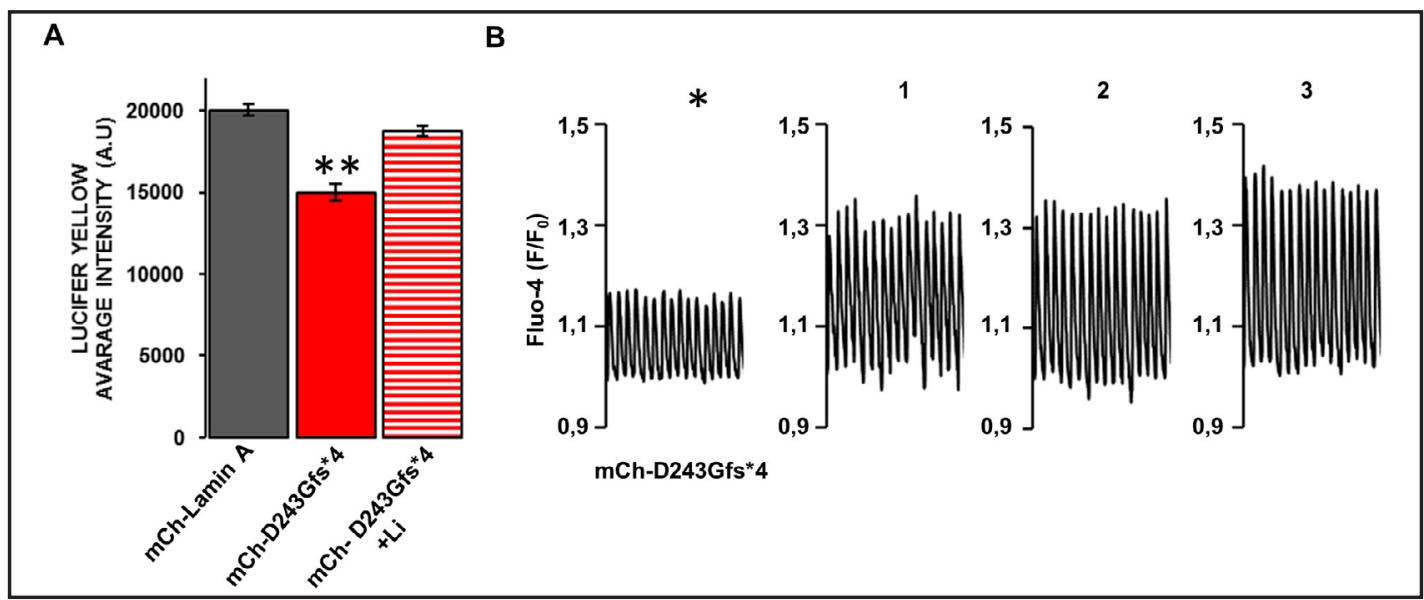

Fig. 10. The expression of mCh-D243Gfs*4 reduces the activity of CX43 in HL-1 cardiomyocytes (A) The fluorescence of LY was evaluated by fluorescence microscopy as described in the methods section. The fluorescence of LY was quantified by the intensity of fluorescence of 15 randomly selected fields with at least 5 cells expressing either mCh-Lamin A or D243Gfs*4, this latter in control condition and after pretreatment overnight with $20 \mathrm{mM}$ Lithium Chloride. Data are expressed as mean \pm S.E. Statistical analysis was performed on three independent experiments and significance calculated by Student's t-test for unpaired samples (LY fluorescence: mCh-Lamin A, 20045 \pm 357.85 , $n=81$ cells versus mCh-D243Gfs*4: $15001.9 \pm 336.25, n=71$, ${ }^{* *} \mathrm{p}<0.01$; mCh-Lamin A, 20045 \pm 357.85, $\mathrm{n}=81$ cells versus mCh-D243Gfs*4+Li: $18745.1 \pm 521.67, \mathrm{n}=51$, p=n.s. (B) HL-1 cells were transfected with mCh-D243Gfs*4, pretreated with Lithium chloride and loaded with Fluo-4. The spontaneous oscillation of four continuous cells were recorded. ${ }^{*}$ indicates transfected with HL1 cells (mCh-D243Gfs*4). 1,2,3 indicate continuous cells not transfected. 


\section{Cellular Physiology Cell Physiol Biochem 2017;44:1559-1577 \\ \begin{tabular}{l|l} 
DOI: 10.1159/000485651 & O 2017 The Author(s). Published by S. Karger AG, Basel \\
www.karger.com/cpb
\end{tabular} \\ Gerbino et al.: Truncating P.D243Gfs*4 LMNA Mutation and Cardiomyopathy}

Overall, these results demonstrated that the reduced protein expression of CX43 may be the possible disease mechanism leading to conduction defects in patients carrying the D243Gfs*4. However, the molecular mechanism responsible of CX43 downregulation upon expression of the D243Gfs*4 is still elusive.

\section{Discussion}

At present, the molecular basis of $L M N A$ induced cardiomyopathy and the cellular events immediately downstream of lamin dysfunction are not yet well understood. Besides, questions regarding the role of $\mathrm{Ca}^{2+}$ signaling and myocardial energetics remain unanswered [28]. Here we present the cellular study of the Lamin A D243Gfs*4 truncating mutant associated to a severe cardiomyopathy outcome.

The D243Gfs*4 LMNA mutant does not share too much characteristics with the previously characterized R321X, whose pathogenic mechanism relies in ER stress-induced programmed cell death with fibro-fatty replacement in the patients.

The fact that the D243Gfs*4 mutant appears 'silent' in terms of UPR, suggests that it aggregates in a tolerated unfolded state probably due to the absence of the entire coil $2 \mathrm{~b}$ protein region, known to be involved in the polymeric head-to-coil assembly of Lamin monomers [29]. Therefore, the putative mechanism that we proposed to explain the arrhythmogenic cardiac phenotype of patients carrying the R321X LMNA variant, seems to be different for D243Gfs*4. To date, several reports have highlighted a link between mutations in LMNA and different functional alterations in other proteins involved in the cardiac intercalated discs assembly (i.e. proteins of the desmosomes, adherens junctions and gap junctions) [1]. One of these proteins, CX43, is in the spotlight right now because alteration in its expression and/ or activity are related with many cardiac pathologies, including cardiac laminopathies, with different extent of intraventricular conduction slowing and QRS prolongation. Mice lacking A-type lamins have decreased $\mathrm{Cx} 43$ levels at the gap junction, potentially contributing to conduction block and arrhythmias [30]. Mutant mice homozygous for the LMNA N195K variation have conduction abnormalities probably linked to the abnormal expression and distributions of connexins (CX40 and CX43) in the heart [10]. In a more recent study, CX43 protein expression was reduced by $40 \%$ in neonatal rat cardiomyocytes transiently transfected with LMNA E82K when compared with the wild-type LMNA cDNA [4].

We have shown that HEK293 cells expressing D243Gfs*4 have reduced level of CX43 expression. The significant reduction of CX43 has been functionally evaluated also in HL-1 cardiomyocytes, whose selective loading of LY and the ability to propagate electric signals were significantly impaired upon expression of D243Gfs*4. We are aware that the cellular mechanisms potentially involved in the observed CX43 reduction are multiple. Recently, the group of Antoine Muchir has identified alterations in several cellular signaling pathway (ERK1/2 [26, 31, 32], AKT/mTOR [33], TGF- $\beta$ [34] just to name a few) in $L M N A^{H 222 P /}$ ${ }_{H 222 P}$ transgenic mice, which recapitulate the cardiac phenotype of human subjects. For example, these mice showed reduced expression of WNT and $\beta$-catenin [9], two signaling proteins implicated in a variety of cellular processes such as proliferation, differentiation and apoptosis. In the absence of WNT stimulation, $\beta$-catenin is phosphorylated by active glycogen synthaser kinase- $3 \beta$ (GSK-3 $\beta$ ) and, subsequently, degraded by the $26 \mathrm{~S}$ proteasome in ubiquitin dependent manner. Conversely, following WNT signaling, GSK-3 $\beta$ is inactivated and $\beta$-catenin can interact both with the gene encoding CX43 to increase its transcription and, likely, with CX43 itself, as part of a multiproteic complex within the intercalated disc [9] to stabilize its structure. Thus, as shown in $\mathrm{LMNA}^{\mathrm{H} 222 \mathrm{P} / \mathrm{H} 222 \mathrm{P}}$ mice, the reduced CX43 expression seems strictly dependent by the deficient WNT/ $\beta$-catenin signaling since the pharmacological rescue of $\beta$-catenin obtained by simply blocking its specific inhibitor (GSK-3 $\beta$ ), completely rescued the level of $\mathrm{CX} 43$. However, even though we experienced a significant reduction of CX43 expression level (HEK293-D243Gfs*4 and HL1-D243Gfs*4 cells) and functional activity (HL 1-D243Gfs*4 cells) we did not see any reduction in active $\beta$-catenin levels upon 


\section{Cellular Physiology Cell Physiol Biochem 2017;44:1559-1577 \begin{tabular}{l|l} 
DOI: 10.1159/000485651 & $\begin{array}{l}\text { O 2017 The Author(s). Published by S. Karger AG, Basel } \\
\text { www.karger.com/cpb }\end{array}$
\end{tabular} \\ Gerbino et al.: Truncating P.D243Gfs*4 LMNA Mutation and Cardiomyopathy}

transfection with D243Gfs*4. This is the reason why we evaluate whether intracellular signaling pathway different from WNT/ $\beta$-catenin could be involved in CX43 impairment. Loss of lamin A impairs the normal sequestration of pERK1/2, resulting in a shift in its localization to the cytoplasm and subsequently inappropriate phosphorylation of Cx43. Loss of LMNA both in vitro and in vivo results in inappropriate ERK1/2 signaling, affecting phosphorylation of Cx43 on S279/282, which reduces intercellular communication. Thus, inappropriate Cx43 phosphorylation may contribute to the conduction defects observed in laminopathies. In addition, Wang and collaborators showed in HL-1 cells that the expression level of CX43 was influenced by RhoA activity, a mechanism that likely contributes to arrhythmogenic cardiomyopathy [13]. Here, however, we did not find significant changes in RhoA activity (RhoA/pRhoA), likely excluding its involvement in CX43 downregulation. Thus, although we did not find any intracellular pathway connecting the expression of the D243Gfs*4 with CX43 down regulation, we provided clear indication about the molecular mechanism involved in the clinical manifestation of this $L M N A$ variant and a possible pharmacological target.

In recent years, mutations of the lamin $\mathrm{A} / \mathrm{C}$ gene have been associated with a combination of morphofunctional phenotypes between DCM and ARVC, suggesting a new (and wider) classification of cardiomyopathies [35]. Patients carrying LMNA variants displayed arrhythmogenic cardiomyopathies with high intra-familial variability, including ARVC, DCM, left ventricular (LV) systolic dysfunction without LV enlargement, system conduction defects and arrhythmias $[4,5,36]$. The patients evaluated in this study and harboring the D243Gfs*4 LMNA mutation are characterized by conduction defect and arrhythmia, which can be both explained by CX43 downregulation in patient's cardiomyocytes. Moreover, it is conceivable that the down regulation of CX43 in cells expressing D243Gfs*4 may be involved also in the fibrosis found in the index patient. Interestingly, it has been demonstrated that the reduced Cx43 expression in a CX43 transgenic mouse model, triggers increased myocardial fibrosis due to enhanced activity of non-excitable cardiac fibroblasts [37]. Of note, this work suggests that early normalization of $\mathrm{Cx} 43$ expression might prevent fibrosis formation and reduce the susceptibility to fatal arrhythmia, underlying the clinical importance in identifying CX43 as the player involved in the cardiomyopathy pathogenesis.

There are no data available on the expression level of the truncated variant in the patient tissues, so we cannot exclude that the Nonsense Mediated Decay of the Messenger (NMD) and haploinsufficiency can be also involved in the pathogenesis of the associated cardiomyopathy.

The heart condition of patient II:1 worsened with the developing of an inflammatory form of cardiomyopathy, with a clinical course retracing that one reported for her mother.

We cannot exclude the involvement of the co-segregating LMNA and RYR2 alterations in the clinical worsening of the cardiac phenotype. As far as we know, while missense mutations in RYR2 gene have been found and clinically associated to the Catecholaminergic Polymorphic Ventricular Tachycardia (CPVT) and the Arrhythmogenic Right Ventricular Cardiomyopathy (ARVC) [38], nonsense mutations in RYR2 have never been described so far. Indeed, the contribution of the RYR2 truncating variant identified in the proband to her cardiac phenotype might be only elusive. We can hypothesize that the very early stop codon occurring in the coding sequence of RYR2 may trigger the NMD mechanism and consequent RYR2 haploinsufficiency. Interestingly, it has been recently shown that RYR2 haploinsufficiency is able to cause significant metabolic abnormalities in cardiomyocytes [39].

Moreover, very recently, a higher incidence of recessive mutations in genes implicated in cardiomyopathy (including BAG3, DSP, PKP2, RYR2, SCN5A and TNNI3) has been demonstrated in patients with acute myocarditis [40]. Also, the potential importance of cytoskeletal and membrane proteins in the pathogenesis of myocarditis is emerging [41]. Thus, although with a still unknown mechanism, RYR2 mutant may contribute the clinical features of the proband. 


\section{Cellular Physiology Cell Physiol Biochem 2017;44:1559-1577 \begin{tabular}{l|l} 
and Biochemistry POI: 10.1159/000485651 & $\begin{array}{l}\text { (c) } 2017 \text { The Author(s). Published by S. Karger AG, Basel } \\
\text { www.karger.com/cpb }\end{array}$
\end{tabular} \\ Gerbino et al.: Truncating P.D243Gfs*4 LMNA Mutation and Cardiomyopathy}

\section{Conclusion}

Our functional data, combined with clinical and genetic findings, indicate D243Gfs*4 LMNA as a disease-causing mutation, and suggest CX43 downregulation as a possible molecular mechanism leading to the conduction defects observed in mutation carriers. The major clinical implication of our findings is that, at least in a cardiomyocytes cell line, the partial restoration of CX43 activity in D243Gfs*4-expressing cells by lithium improved cellto-cell signal propagation thus suggesting CX43 as potential pharmaceutical target for this form of cardio-laminopathy. Also, the co-occurrence of LMNA and RYR2 mutations might be associated to the developing of myocarditis and severe cardiac outcome. Thus, our results confirm the emergent role of the LMNA gene in the pathogenesis of a wide spectrum of cardiomyopathies.

\section{Disclosure Statement}

None to declare.

\section{Acknowledgements}

This work was supported by funding from the CLUSTER TECNOLOGICO REGIONALE "DICLIMAX" (project \# MTJU9H8) to Maria Svelto and from the department of Molecular Medicine, Sapienza University of Rome to Paola Grammatico. We are very grateful to Dr. Daniela Russo, Dr. Rocchina Miglionico and Dr. Marco Castori for expert technical and clinical assistance.

\section{References}

1 Carmosino M, Torretta S, Procino G, Gerbino A, Forleo C, Favale S, Svelto M: Role of nuclear lamin a/c in cardiomyocyte functions. Biol Cell 2014;106:346-358.

2 Andrés V, González JM: Role of a-type lamins in signaling, transcription, and chromatin organization. J Cell Biol 2009;187:945-957.

3 Lu JT, Muchir A, Nagy PL, Worman HJ: Lmna cardiomyopathy: Cell biology and genetics meet clinical medicine. Dis Model Mech 2011;4:562-568.

4 Cattin ME, Muchir A, Bonne G: 'State-of-the-heart' of cardiac laminopathies. Curr Opin Cardiol 2013;28:297-304.

5 Forleo C, Carmosino M, Resta N, Rampazzo A, Valecce R, Sorrentino S, Iacoviello M, Pisani F, Procino G, Gerbino A, Scardapane A, Simone C, Calore M, Torretta S, Svelto M, Favale S: Clinical and functional characterization of a novel mutation in lamin a/c gene in a multigenerational family with arrhythmogenic cardiac laminopathy. PloS one 2015;10:e0121723.

6 Al-Saaidi R, Rasmussen TB, Palmfeldt J, Nissen PH, Beqqali A, Hansen J, Pinto YM, Boesen T, Mogensen J, Bross P: The Imna mutation p.Arg321ter associated with dilated cardiomyopathy leads to reduced expression and a skewed ratio of lamin a and lamin c proteins. Exp Cell Res 2013;319:3010-3019.

7 Geiger SK, Bär H, Ehlermann P, Wälde S, Rutschow D, Zeller R, Ivandic BT, Zentgraf H, Katus HA, Herrmann $\mathrm{H}$, Weichenhan D: Incomplete nonsense-mediated decay of mutant lamin a/c mrna provokes dilated cardiomyopathy and ventricular tachycardia. J Mol Med (Berl) 2008;86:281-289.

8 Carmosino M, Gerbino A, Schena G, Procino G, Miglionico R, Forleo C, Favale S, Svelto M: The expression of lamin a mutant $\mathrm{r} 321 \mathrm{x}$ leads to endoplasmic reticulum stress with aberrant ca(2+) handling. J Cell Mol Med 2016;20:2194-2207.

-9 Le Dour C, Macquart C, Sera F, Homma S, Bonne G, Morrow JP, Worman HJ, Muchir A: Decreased wnt/ $\beta$ catenin signalling contributes to the pathogenesis of dilated cardiomyopathy caused by mutations in the lamin a/c gene. Hum Mol Genet 2017;26:333-343. 


\section{Cellular Physiology Cell Physiol Biochem 2017;44:1559-1577 \begin{tabular}{ll|l} 
and BiOChemistry & $\begin{array}{l}\text { DOI: 10.1159/000485651 } \\
\text { Published online: December 04, } 2017\end{array}$ & $\begin{array}{l}\text { (c) } 2017 \text { The Author(s). Published by S. Karger AG, Basel } \\
\text { www.karger.com/cpb }\end{array}$ \\
\hline
\end{tabular}

10 Mounkes LC, Kozlov SV, Rottman JN, Stewart CL: Expression of an lmna-n195k variant of a-type lamins results in cardiac conduction defects and death in mice. Hum Mol Genet 2005;14:2167-2180.

11 Sun LP, Wang L, Wang H, Zhang YH, Pu JL: Connexin 43 remodeling induced by lmna gene mutation glu82lys in familial dilated cardiomyopathy with atrial ventricular block. Chin Med J (Engl) 2010;123:10581062.

12 Muchir A, Wu W, Sera F, Homma S, Worman HJ: Mitogen-activated protein kinase kinase 1/2 inhibition and angiotensin ii converting inhibition in mice with cardiomyopathy caused by lamin a/c gene mutation. Biochem Biophys Res Commun 2014;452:958-961.

13 Wang L, Liu S, Zhang H, Hu S, Wei Y: Rhoa activity increased in myocardium of arrhythmogenic cardiomyopathy patients and affected connexin 43 protein expression in hl-1 cells. Int J Clin Exp Med 2015;8:12906-12913.

14 White SM, Constantin PE, Claycomb WC: Cardiac physiology at the cellular level: Use of cultured hl-1 cardiomyocytes for studies of cardiac muscle cell structure and function. Am J Physiol Heart Circ Physiol 2004;286:H823-829.

15 Palmer AE, Jin C, Reed JC, Tsien RY: Bcl-2-mediated alterations in endoplasmic reticulum ca2+ analyzed with an improved genetically encoded fluorescent sensor. Proceedings of the National Academy of Sciences of the United States of America 2004;101:17404-17409.

16 Gerbino A, Schena G, Milano S, Milella L, Barbosa AF, Armentano F, Procino G, Svelto M, Carmosino M: Spilanthol from acmella oleracea lowers the intracellular levels of camp impairing nkcc2 phosphorylation and water channel aqp2 membrane expression in mouse kidney. PloS one 2016;11:e0156021.

17 Carmosino M, Gerbino A, Hendy GN, Torretta S, Rizzo F, Debellis L, Procino G, Svelto M: Nkcc2 activity is inhibited by the bartter's syndrome type 5 gain-of-function car-a843e mutant in renal cells. Biol Cell 2015;107:98-110.

18 Grynkiewicz G, Poenie M, Tsien RY: A new generation of ca2+ indicators with greatly improved fluorescence properties. J Biol Chem 1985;260:3440-3450.

19 Bottillo I, D’Angelantonio D, Caputo V, Paiardini A, Lipari M, De Bernardo C, Giannarelli D, Pizzuti A, Majore S, Castori M, Zachara E, Re F, Grammatico P: Molecular analysis of sarcomeric and non-sarcomeric genes in patients with hypertrophic cardiomyopathy. Gene 2016;577:227-235.

20 Muchir A, Massart C, van Engelen BG, Lammens M, Bonne G, Worman HJ: Proteasome-mediated degradation of integral inner nuclear membrane protein emerin in fibroblasts lacking a-type lamins. Biochem Biophys Res Commun 2006;351:1011-1017.

-21 Oslowski CM, Urano F: Measuring er stress and the unfolded protein response using mammalian tissue culture system. Methods Enzymol 2011;490:71-92.

-22 Pirot P, Ortis F, Cnop M, Ma Y, Hendershot LM, Eizirik DL, Cardozo AK: Transcriptional regulation of the endoplasmic reticulum stress gene chop in pancreatic insulin-producing cells. Diabetes 2007;56:10691077.

23 Chaitanya GV, Steven AJ, Babu PP: Parp-1 cleavage fragments: Signatures of cell-death proteases in neurodegeneration. Cell Commun Signal 2010;8:31.

-24 Belmokhtar CA, Hillion J, Ségal-Bendirdjian E: Staurosporine induces apoptosis through both caspasedependent and caspase-independent mechanisms. Oncogene 2001;20:3354-3362.

25 Patel D, Zhang X, Veenstra RD: Connexin hemichannel and pannexin channel electrophysiology: How do they differ? FEBS Lett 2014;588:1372-1378.

26 Muchir A, Shan J, Bonne G, Lehnart SE, Worman HJ: Inhibition of extracellular signal-regulated kinase signaling to prevent cardiomyopathy caused by mutation in the gene encoding a-type lamins. Hum Mol Genet 2009;18:241-247.

27 Dias P, Desplantez T, El-Harasis MA, Chowdhury RA, Ullrich ND, Cabestrero de Diego A, Peters NS, Severs NJ, MacLeod KT, Dupont E: Characterisation of connexin expression and electrophysiological properties in stable clones of the hl-1 myocyte cell line. PloS one 2014;9:e90266.

28 Brayson D, Shanahan CM: Current insights into lmna cardiomyopathies: Existing models and missing lincs. Nucleus 2017;8:17-33.

29 Strelkov SV, Schumacher J, Burkhard P, Aebi U, Herrmann H: Crystal structure of the human lamin a coil 2b dimer: Implications for the head-to-tail association of nuclear lamins. J Mol Biol 2004;343:1067-1080.

-30 Chen SC, Kennedy BK, Lampe PD: Phosphorylation of connexin43 on s279/282 may contribute to laminopathy-associated conduction defects. Exp Cell Res 2013;319:888-896. 


\section{Cellular Physiology Cell Physiol Biochem 2017;44:1559-1577 \begin{tabular}{l|l} 
DOI: 10.1159/000485651 & O 2017 The Author(s). Published by S. Karger AG, Basel \\
www.karger.com/cpb
\end{tabular} \\ Gerbino et al.: Truncating P.D243Gfs*4 LMNA Mutation and Cardiomyopathy}

-31 Muchir A, Reilly SA, Wu W, Iwata S, Homma S, Bonne G, Worman HJ: Treatment with selumetinib preserves cardiac function and improves survival in cardiomyopathy caused by mutation in the lamin a/c gene. Cardiovasc Res 2012;93:311-319.

-32 Wu W, Muchir A, Shan J, Bonne G, Worman HJ: Mitogen-activated protein kinase inhibitors improve heart function and prevent fibrosis in cardiomyopathy caused by mutation in lamin a/c gene. Circulation 2011;123:53-61.

-33 Choi JC, Muchir A, Wu W, Iwata S, Homma S, Morrow JP, Worman HJ: Temsirolimus activates autophagy and ameliorates cardiomyopathy caused by lamin a/c gene mutation. Sci Transl Med 2012;4:144ra102.

-34 Chatzifrangkeskou M, Le Dour C, Wu W, Morrow JP, Joseph LC, Beuvin M, Sera F, Homma S, Vignier N, Mougenot N, Bonne G, Lipson KE, Worman HJ, Muchir A: Erk1/2 directly acts on ctgf/ccn2 expression to mediate myocardial fibrosis in cardiomyopathy caused by mutations in the lamin a/c gene. Hum Mol Genet 2016;25:2220-2233.

-35 Arbustini E, Narula N, Dec GW, Reddy KS, Greenberg B, Kushwaha S, Marwick T, Pinney S, Bellazzi R, Favalli V, Kramer C, Roberts R, Zoghbi WA, Bonow R, Tavazzi L, Fuster V, Narula J: The moge(s) classification for a phenotype-genotype nomenclature of cardiomyopathy: Endorsed by the world heart federation. J Am Coll Cardiol 2013;62:2046-2072.

-36 Charron P, Arad M, Arbustini E, Basso C, Bilinska Z, Elliott P, Helio T, Keren A, McKenna WJ, Monserrat L, Pankuweit S, Perrot A, Rapezzi C, Ristic A, Seggewiss H, van Langen I, Tavazzi L, Diseases ESoCWGoMaP: Genetic counselling and testing in cardiomyopathies: A position statement of the european society of cardiology working group on myocardial and pericardial diseases. Eur Heart J 2010;31:2715-2726.

-37 Jansen JA, van Veen TA, de Jong S, van der Nagel R, van Stuijvenberg L, Driessen H, Labzowski R, Oefner CM, Bosch AA, Nguyen TQ Goldschmeding R, Vos MA, de Bakker JM, van Rijen HV: Reduced cx43 expression triggers increased fibrosis due to enhanced fibroblast activity. Circ Arrhythm Electrophysiol 2012;5:380390.

-38 Taur Y, Frishman WH: The cardiac ryanodine receptor (ryr2) and its role in heart disease. Cardiol Rev 2005;13:142-146.

39 Bround MJ, Wambolt R, Cen H, Asghari P, Albu RF, Han J, McAfee D, Pourrier M, Scott NE, Bohunek L, Kulpa JE, Chen SR, Fedida D, Brownsey RW, Borchers CH, Foster LJ, Mayor T, Moore ED, Allard MF, Johnson JD: Cardiac ryanodine receptor (ryr2)-mediated calcium signals specifically promote glucose oxidation via pyruvate dehydrogenase. J Biol Chem 2016;291:23490-23505.

40 Belkaya S, Kontorovich AR, Byun M, Mulero-Navarro S, Bajolle F, Cobat A, Josowitz R, Itan Y, Quint R, Lorenzo L, Boucherit S, Stoven C, Di Filippo S, Abel L, Zhang SY, Bonnet D, Gelb BD, Casanova JL: Autosomal recessive cardiomyopathy presenting as acute myocarditis. J Am Coll Cardiol 2017;69:1653-1665.

41 Lim BK, Peter AK, Xiong D, Narezkina A, Yung A, Dalton ND, Hwang KK, Yajima T, Chen J, Knowlton KU: Inhibition of coxsackievirus-associated dystrophin cleavage prevents cardiomyopathy. J Clin Invest 2013;123:5146-5151. 